Portland State University

PDXScholar

Fall 12-19-2019

\title{
Student Sustainability Leadership Development at Portland State University: Developing Holistic Sustainability Leaders
}

Megan Suzanne Schneider

Portland State University

Follow this and additional works at: https://pdxscholar.library.pdx.edu/open_access_etds

Part of the Higher Education Commons, and the Sustainability Commons Let us know how access to this document benefits you.

Recommended Citation

Schneider, Megan Suzanne, "Student Sustainability Leadership Development at Portland State University: Developing Holistic Sustainability Leaders" (2019). Dissertations and Theses. Paper 5361.

https://doi.org/10.15760/etd.7234

This Thesis is brought to you for free and open access. It has been accepted for inclusion in Dissertations and Theses by an authorized administrator of PDXScholar. Please contact us if we can make this document more accessible: pdxscholar@pdx.edu. 
Student Sustainability Leadership Development at Portland State University:

Developing Holistic Sustainability Leaders

by

Megan Suzanne Schneider

A thesis submitted in partial fulfillment of the requirements for the degree of

\author{
Master of Science \\ in \\ Education: Educational Leadership and Policy
}

Thesis Committee:

Heather Burns, Chair

Dilafruz Williams

Christine Cress

Portland State University

2019 


\begin{abstract}
In order to address the myriad of social, economic, and environmental challenges the world is facing, we need to be able to engage in leadership that fosters collective action towards sustainable solutions. Higher education is an institution that can equip people with the abilities to engage in sustainability leadership. This master's thesis research explores how students develop sustainability leadership through their college experience. Nine students, who had been identified as sustainability leaders through their participation in the Student Sustainability Center (SSC), a co-curricular sustainability program at Portland State University, were selected to be part of this grounded theory research project. The results showed that student sustainability leadership was supported primarily by developing a sustainability oriented community, a holistic understanding of sustainability, and a holistic self. These findings align with the literature on sustainability leadership, as sustainability leadership requires a complex, integrated, and holistic understanding of sustainability concepts, and of oneself, in order to work relationally with others towards change. The results of the study suggest that the SSC offers effective sustainability leadership development opportunities for students by providing programming that reflects the sustainability leadership values the program holds. This study also offers a critical perspective that begins to examine how sustainability leadership ought to be held accountable to Indigenous perspectives that bring dominant power systems into question in order to dismantle the systems that cause unsustainability.
\end{abstract}




\section{Acknowledgements}

Throughout the process of doing my thesis I have come to see my lived experience reflected in my research. I would not have been able to do this project without my community.

I offer my gratitude to Heather Spalding, the project partner; this project would not have been possible in any way without you. I also have the deepest gratitude for Dr. Heather Burns and Dr. Sybil Kelley, my advisors, who offered me support and guidance through this project even when they were both stretched thin. I would also like to thank Dr. Ho'esta Mo'e'hahne and Dr. Derrais Carter, two former PSU faculty who completely changed my scholarship and the way I see the world. Thank you to my committee members Dr. Dilafruz Williams and Dr. Christine Cress for participating in and being part of my work as well.

I would also like to thank my wider community for all the support I have received. A huge thank you to my friends, especially Kenzie Eiden, Lilly Harris, Dara McDevitt, and Ried Gustafson, to my mother Dawn Schneider and my aunt Deb Weeks, and to my partner Jesse Autuchovich, for your endless support and encouragement. Thank you to my therapist for helping me organize my life in a way that I could get this thing done. Thank you to my bosses and co-workers who supported me when I needed time off to work on this project. Thank you to the students who participated in this research. And thank you to everyone else along the way, from a mentor who told me to write early in the morning to a regular at one of my yoga classes who recommended a great writing book to me. This has truly been a community effort, and for that I am truly grateful. 


\section{Table of Contents}

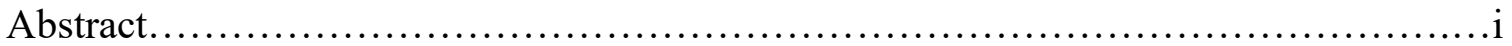

Acknowledgements...........................................................

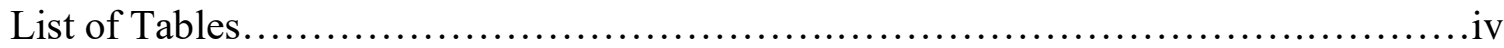

List of Figures..............................................................

Chapter I

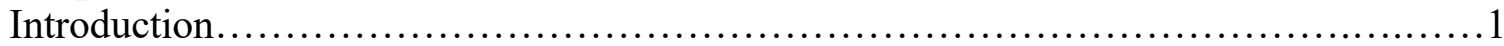

Chapter II

Literature Review.......................................................14

Chapter III

Methods....................................................................... 65

Chapter IV

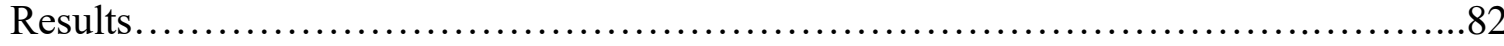

Chapter V

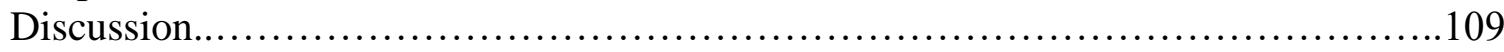

References.............................................................. 125

Appendix A: Student Sustainability Center Leadership Fellows Syllabus (2017-18)

Course Overview........................................................ 132

Appendix B: Recruitment Email............................................... 133

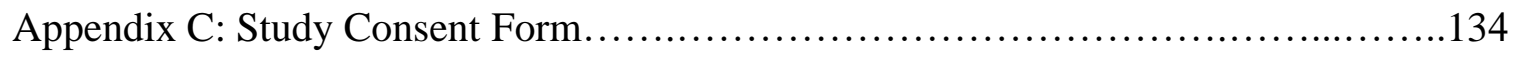

Appendix D: Semi-Structured Interview Questions.............................138 


\section{List of Tables}

Table 1. Themes that Support Student Sustainability Leadership Development..........83

Table 2. Student Sustainability Leadership Themes in Program Design................105 


\section{List of Figures}

Figure 1. The Social Change Model of Leadership...................................31

Figure 2. Student Sustainability Center Program Sitemap........................... 71 


\section{Chapter I}

\section{Introduction}

As our global community continues to face increasingly frequent and more severe ecological crises, while grappling with social injustices that have troubled humanity for centuries, the need for radical rethinking and action grows. Sustainability has developed throughout the past half century as a Western concept and academic field of study in an attempt to address these global challenges and the mindsets that contribute to them. Sustainability, in its relative conceptual infancy, is a nebulous idea with many definitions and applications. It is normatively thought of as attempting to ensure that society's actions in the present do not compromise the ability of future generations to live out their lives (Brundtland, 1987). In more recent conceptualizations, sustainability is seen as a process that involves "changing our ways of being and working collaboratively to create regenerative, interconnected, just, and thriving systems and communities" (Burns, 2016, p. 1). In order to effectively engage in working towards sustainability and ensure a future for the human race, people who are equipped to bring about transformative change for sustainability are needed. Leadership, another complex concept that involves people working together to enact change, can make important contributions to sustainability efforts. Together these concepts have come to be known as sustainability leadership or leadership for sustainability, a concept that provides a framework for understanding the process of people working towards transformative change for a more sustainable world.

Higher education, a social institution that has the potential to generate innovation and change, has been identified as a site in which sustainability leadership can be taught, cultivated, and enacted, thus fostering a collective of people equipped with the leadership 
abilities to tackle the complex and multidimensional challenges that the global community faces today (Burns, 2016; Kerr \& Hart-Steffes, 2010; Shriberg \& MacDonald, 2013). The growth of sustainability leadership as a field of study within higher education, as well as a potential intended learning outcome of higher education, has led to a plethora of academic and co-curricular programs that support the development of sustainability leaders (Shriberg \& MacDonald, 2013). However, given the recent emergence of sustainability leadership and its growing societal importance, there remains much to be learned about how to best support sustainability leadership development in higher education.

\section{Sustainability: Tracing the Concept}

Sustainability as a term and concept within dominant Western society can be understood as having its origins in the settler-colonial nation of the United States (US), within the context of global European colonization (Evans, 2018; Tuck \& Yang, 2012). In their seminal article Decolonization is not a Metaphor, Eve Tuck, of the Unangax people, and K. Wayne Yang (2012) define settler colonialism as a system in which settlers (people who arrive to the land) attempt to remake and control native or Indigenous (people who were on the land before settlers arrived) land as their own place to live and as a source of economic capital. The set of relationships between settlers, natives, and slaves (people who are brought to the land as property) greatly impacts people's relationships to land and the natural world, as well as social structures within the societies and cultures of settler-colonial nation states. The land currently known as the United States is experiencing ongoing settler colonialism and it is within this context that the conversation about sustainability must be understood. 
Western societies are in part based on a dualistic mindset that views humans and nature as separate (Evans, 2018). This way of thinking and being contributes to hierarchical power structures and systems that create subjugated "others;" these subjugated others include certain genders (non-male, non-binary, trans), races (nonwhite), and non-Western cultures, such as Indigenous cultures, as well as the natural world (Evans, 2018). The social and cultural structures of settler colonialism and their accompanying dualistic power hierarchies have made dominant social systems, discourses, and ideologies possible, such as the capitalist economic system, white supremacy, and the justified erasure of Indigenous cultures and life-worlds (Tuck \& Yang, 2012). To be maintained, these social structures not only cause but require conditions of inequity and oppression that materially and negatively affect people's lives, as well as perpetuate and require disconnection from and destruction of the natural world (Evans, 2010; Shriberg, 2012). In addition to these hierarchical power structures, Western thought is also largely based on the principles of Newtonian science (Wheatley, 2006). Newtonian science gives primacy to reason and views the world as linear, mechanistic, and controllable (Wheatley, 2006). These ways of knowing and being can in large part explain the industrialized and mechanized economic system based on scientific management found in the US during the 20th century, which has contributed to the rapid degradation of the natural world (Shriberg, 2012).

Many social systems and structures within dominant US society have been built on the basis of Western scientific thought and the relationships found within settler colonialism, including the social and political movements that the discourse of sustainability emerged from. Sustainability, as a movement and a concept, can be 
understood as having its conceptual roots in the conservation, preservation, and environmental movements that arose in the 20th century US (National Research Council, 2011). Through these movements, a growing awareness of human impact on the natural world and non-human life, as well as increasingly visible issues related to injustice and inequity, led people in the US and around the world to begin to question the systems of industrialization and mechanization typical to a globalizing colonial Western society (Shriberg, 2012). However, sustainability and the movements that preceded it were formed out of the Western mindset. Because of their position within dominant Western society, the movements that contributed to the emergence of sustainability failed to acknowledge the context of the ongoing settler colonialism occurring within the US that they arose from and often did not incorporate Indigenous peoples or their perspectives (Grande, 2004).

Sustainability as a concept became politically, socially, and culturally solidified in the 1970's and 1980's with moments such as the formation of the US Environmental Protection Agency and the first Earth Day in 1970 (National Research Council, 2011). This occurred on an international scale as well with the publication of the seminal report Our Common Future, also known as the Brundtland Report, in 1987 (Kerr \& HartSteffes, 2012). In international conversations, the term sustainable development was institutionalized at the 1992 United Nations Conference on Environment and Development (National Research Council, 2011). This term laid the foundation for one of the most commonly used frameworks for sustainability today, the "three pillars of sustainability." These pillars include the social, economic, and environmental, which incorporated the social and economic aspects of development along with environmental 
protection (National Research Council, 2011). Another lasting conceptualization of sustainability that formed during that time was the Brundtland Report's definition of sustainability as "the ability... to ensure that [sustainable development] meets the needs of the present without compromising the ability of future generations to meet their own needs" (Brundtland, 1987, p. 43).

Since that time, sustainability has grown into its own academic field of study, professional field, and leadership style. Although the term has taken on a myriad of meanings and is somewhat contested, sustainability can be thought of as a framework that combines ecological, social, and economic considerations when finding ways to address the complex issues facing our global community, from poverty to climate change, that stem from dominant social and political systems and structures (Burns, 2016; Ferreira, 2017; Shriberg, 2012). As Mary Ferdig (2007), a prominent sustainability scholar, writes: Sustainability can be described as each of us doing our part to build the kind of world that we want to live in and that we want our children and grandchildren to inherit. It means becoming aware of choices and behaviors that influence the intricate balance of the earth's social, ecological, and economic systems, and then expanding that awareness through conversations that can lead to joint action. (p. 28)

Sustainability can be understood as a holistic way of thinking that aims at creating a better world by engaging in actions that foster systemic change towards more just and healthy communities.

People who are able to embody a sustainable way of thinking and being are needed in order to work towards solutions to our world's complex challenges. Leadership 
for sustainability, or sustainability leadership, has recently become a topic of theorization within academia. Sustainability leadership seeks to combine the fields of sustainability and leadership in order to contribute to a collective of people able to address the challenges of unsustainability.

\section{Leadership: Defining the Concept}

Leadership, like sustainability, is an amorphous concept with a wide variety of meanings and usages in both academia and US culture. The meaning of leadership is often interpreted by those engaging with the term based on their life histories; for each individual, leadership can mean anything from an internalized identity, civic engagement, activism, and positive group experiences, to associations with abuses of power, positionality, or achieving end goals (Komives \& Dugan, 2010). Leadership as a field of study, like most disciplines within academia, has its epistemological basis in linear and mechanistic Newtonian science (Wheatley, 2006). For many years, leaders were normatively considered to be those people that held dominant positions in society and leadership was understood as something done by leaders. Komives and Dugan (2010) describe this view:

Leadership typically reflected leader-centric approaches focusing on the leader as a positional authority. Largely examined in organizational or management contexts, these perspectives led to theories and research on how positional leaders accomplished goals in organizational settings, on what traits and styles were effective to achieve outcomes, and eventually on how the leader influenced others in the organization. (p. 111) 
This traditional view of leaders and leadership parallels dominant Western ways of thinking, which views people as cogs in the industrial machine, operates with hierarchy, and focuses on goals of production within a capitalist economic system (Shriberg, 2012).

However, leadership has since come to be understood in a different way. Leadership, in theory as well as outside of academia, is now often thought of as a process of engaging in transformative change with, not over, others (Rost, 1997). Notions of who leaders are and what leadership is have shifted from defining the role of hierarchical, positional leaders to exploring how people can engage relationally with others to influence mutual change (Rost, 1997). People are also beginning to apply concepts from the new sciences such as quantum physics and chaos theory to understand organizational leadership in a new way beyond Newtonian science (Wheatley, 2006). These shifts have been instrumental in rethinking the theory, practice, and education of leadership.

\section{Leadership Applied to College Students and Sustainability}

Alongside the shift in how leaders and leadership were understood arose new applications of these theories. One of these new veins of leadership studies was leadership for students within higher education. Of particular importance in leadership for college students is student leadership development, or the concept of how college students can learn and gain capacities to engage in leadership. Teaching leadership development to students through academic and co-curricular experiences has become common in higher education, and many institutions have even defined leadership as an important outcome of the college experience (Eich, 2008). Furthermore, research has demonstrated that higher education can contribute to increasing leadership abilities in students (Dugan \& Komives, 2010). Student leadership and leadership development are 
often taught through the lens of a relational understanding of leadership, with the goal of fostering students able to engage with others in social change in an increasingly complex world (Dugan \& Komives, 2011).

Another emerging leadership style is sustainability leadership. Proponents of sustainability leadership (Bendell \& Little, 2015; Burns, 2016; Evans, 2018; Ferdig, 2007; Shriberg \& MacDonald, 2013) argue that a new form of leadership is needed in order to promote positive change in the dominant social, cultural, and economic systems that are causing ecological degradation and social injustices. Sustainability leadership, with its emphasis on the natural world, justice, collaboration, complexity, and connection, is understood to be radically different than traditional conceptualizations of leaders and leadership. This form of leadership, with roots in theories such as the new sciences, systems theory, and relational models of leadership, provides an alternative to the mechanistic, industrial, and hierarchical forms of leaders and leadership. Sustainability leadership thus challenges both the dominant conceptualization of leadership and the ways of thinking that cause unsustainability. Indeed, some sustainability leadership scholars view sustainability and leadership as inextricably connected given that the complex challenges we face require leadership and leadership must now consider incorporating sustainability into its core aim due to the severity of these challenges (Burns, Diamond-Vaught, \& Bauman, 2015). This connection between sustainability and leadership theory "is critical because the transition to a sustainable world urgently demands new leadership" (Shriberg, 2012, p. 470). Sustainability leadership ultimately seeks to motivate and activate people so they may collectively address the troubles of our times. 


\section{Sustainability Leadership in Higher Education}

Higher education has been identified as a site where leadership development, sustainability, and sustainability leadership can be taught. In fact, because sustainability work will require people who are able to effectively create change with others, leadership development has come to be thought of as an important part of sustainability education (Burns, 2016). Kerr and Hart-Steffes (2012) describe sustainability's potential position in higher education:

It is logical that the pursuit of healthy environments, social justice, and strong economies be found on college campuses. It makes sense that on college campuses, faculty, staff, and students strive to understand how our society can develop the ability to provide for the needs of the current generation without compromising the ability of future generations to meet their needs (World Commission on Environment and Development [WCED], 1987). In reality, this simple goal is actually an incredibly complex endeavor: one that is served well by the great minds and thinking found at colleges and universities. (p. 7)

Higher education, while still primarily underpinned by dominant Western epistemologies, can be an institution that generates critical thinking and creative innovations that serve the goal of working towards a more sustainable world. The role that higher education can play in developing leaders for sustainability is both one of fit and imperative; it is imperative that institutions across society, including higher education, begin to take their responsibility in fostering changemakers able to address the challenges of unsustainability seriously. While sustainability leadership in higher education has been positioned as a path towards more just and healthy communities, it is 
important to acknowledge the context of settler colonialism that sustainability leadership arose from, as this perspective provides an opportunity to steer the trajectory of the sustainability movement towards one that incorporates Indigenous peoples in the goal of overcoming unsustainable ideologies and practices.

\section{Sustainability at Portland State University}

This research took place at Portland State University (PSU), a public university of approximately 27,000 students in downtown Portland, Oregon. PSU's motto "Let Knowledge Serve the City" creates an institutional environment well-suited for experiential learning and civic engagement. In addition to its engagement-oriented ethos, PSU is known for its sustainability efforts and is often recognized in national sustainability rankings (“Awards \& Certifications", 2019). Sustainability also has a place in the institutional fabric of the university, as the term is mentioned in the vision, mission, and values statements of the university's current strategic plan (Portland State University Strategic Plan 2016-2020, n.d.). In alignment with this institutional commitment to sustainability, a broad range of programs and strategies for implementing sustainability initiatives exist at PSU including: undergraduate and graduate pathways, degrees, and certificates that focus on sustainability; a university-wide undergraduate sustainability learning outcome; co-curricular programs; and support, networks, and funding for faculty and research on sustainability.

In 2008, PSU was awarded a $\$ 25$ million grant by the Miller Foundation, which was used to support PSU in becoming a regional and national leader in teaching, research, and community engagement focused on sustainability. At the time, the Miller Foundation award was the largest gift in the history of PSU and was also "perhaps the 
largest single gift to sustainability in U.S. higher education history" ("The James F. and Marion L. Miller Foundation Gift”, 2019). The grant money was used to fund the Institute for Sustainable Solutions (ISS), an institute at PSU that focuses on sustainability-related initiatives, projects, and programs across the university. Some of the ISS programs include: funding internships and other professional development opportunities for students; creating and supporting mentorship programs and networks of sustainability faculty, students, and professionals across the campus and city; and funding and supporting sustainability-related faculty projects and research.

\section{The Student Sustainability Center}

One of the programs that spawned from ISS was the Student Sustainability Center (SSC), formerly known as the Sustainability Leadership Center. The SSC was started as a co-curricular sustainability program in 2009 "with the mission of integrating sustainability into the student life experience" (Spalding, Williams, \& Wise, 2014, p. 3). From its origins, the SSC held a unique place within PSU as it was funded by ISS but reported to the Dean of Student Life in Enrollment Management and Student Affairs (EMSA). In the 2016-17 academic year, the SSC undertook a planned transition of its organizational location to become fully housed in Student Activities and Leadership Programs (SALP) within EMSA (Student Sustainability Center 2016-17 Impact Report, n.d.).

The SSC provides "peer-to-peer experiential learning programs [that] offer a 'web of opportunities' for students to participate in and co-create collaborative intentional learning communities" (Spalding, Williams, \& Wise, 2014, p. 6). The vision of the SSC is to "empower all students to be keepers of an interdependent, healthy, regenerative 
world" and the mission is "to be an accessible hub that integrates sustainability with the student experience through transformational learning opportunities” (“About Us”, 2019). The SSC offers a variety of programming, including student run task forces that focus on specific sustainability topics, an Ecoreps program, a leadership council, and on-campus events. Throughout its programs, "the SSC utilizes a holistic perspective of sustainability that integrates systems thinking, social justice, deep ecology, participatory processes, and wellness into its sustainability leadership philosophy" (Spalding, Williams, \& Wise, 2014, p. 3). The SSC, with its institutional location in SALP and its thematic focus on sustainability, represents a unique organizational opportunity to put sustainability leadership and student leadership development theories into practice with one another.

\section{The Research}

The Student Sustainability Center (SSC) Program Coordinator initiated and conducted a research project in 2015 meant to explore how students became involved with sustainability at PSU and developed into sustainability leaders. I conducted a second phase of this same project for my master's thesis. The primary research questions guiding the study were 1) "How are student sustainability leaders developed at PSU?" and 2) "How can staff support or encourage the development of student sustainability leaders?" In order to better understand the nexus of student leadership development and sustainability leadership in co-curricular sustainability programming at PSU, this study employed pragmatic and qualitative methodologies to fulfill the SSC Program Coordinator's desire to explore this phenomenon. Students who had been identified as sustainability leaders were selected and interviewed and the data was analyzed using grounded theory methodology. 


\section{Overview of Chapters}

The second chapter reviews the literature in the areas of leadership and leadership development, student leadership and student leadership development in higher education, and sustainability leadership and sustainability leadership development in higher education. The literature review provides an overview of these concepts, summarizes previous research, and connects the different concepts to provide a theoretical foundation for this study. The third chapter presents the methodology of this study, including the research design, limitations and significance of the research. The fourth chapter presents the results of the data collection and analysis. The fifth chapter discusses the results in relation to the literature and provides final recommendations and a conclusion of the study. 


\section{Chapter II \\ Literature Review}

\section{Introduction}

Leadership has the potential to make important contributions in working towards solutions to unsustainable systems and mindsets. An understanding of leadership and its evolution as a concept in dominant society and as an academic field is helpful to understanding the development of and relationship between leadership, student leadership, and sustainability leadership, as well as how these can be applied to addressing sustainability challenges.

This literature review will start with an exploration of leadership theories and their evolution, as well as theories and models of leadership development. The second section examines leadership models and leadership development specifically as they relate to students in institutions of higher education. The final section reviews the emergence of sustainability leadership, explores what sustainability leadership is, and how sustainability leadership is developed in students in higher education.

\section{What is Leadership?}

From industrial to postindustrial and beyond. Leadership as a concept and Western subject of study came into existence in the 20th century (Rost, 1997). Throughout the history of leadership, prevailing epistemologies have influenced theorizations on leaders and leadership, as theories are generated from the ways of knowing that underpin them (Komives \& Dugan, 2010). In turn, changing theories of leadership have led to changes in leadership practices and education, as well as perspectives on leader and leadership development (Komives, 2011). 
In their article Contemporary Leadership Theories, Komives and Dugan (2010) explore the epistemological history of leadership and offer a description of the theorizations of leaders and leadership that originated in the early 20th century. These early theories, which reflected dominant epistemological paradigms of the time, centered on "great man" models of leadership and were based on the idea that leadership is in essence "... a leader, followers, and the things leaders get followers to follow" (Hull, Robertson, \& Mortimer, 2018, p. 171). Komives and Dugan explain that "these theories reflected prevailing social constructions of leadership that were associated with traditionally masculine, industrial, and structural approaches... such as hierarchical relationships, achievement orientations, and leveraging of power" (p. 111). In her article on sustainable leadership, Evans (2018) describes how these conceptualizations and practices of leadership are underpinned by centuries of European colonization that enabled the transmission of mindsets, social structures, economies, and cultures built on power inequities and constructions of "otherness" across the globe. These constructions of and approaches to leadership have commonly come to be referred to as "industrial leadership," a term attributed to Joseph Rost's (1997) seminal article Moving from individual to relationship: A postindustrial paradigm of leadership, in which Rost traces the history and evolution of the discipline of leadership.

Industrial leadership emphasizes individual leaders as people who do leadership (Rost, 1997). Although industrial leadership theories have morphed throughout the 20th century, their focus lies on how individuals are enabled to do leadership. These industrial leadership theories included trait-based models in the early 1900s, which posited that the characteristics or personal attributes that people were born with, not that they developed, 
were what made them leaders (Komives \& Dugan, 2010). A subsequent focus of study, behavioral leadership theories, emphasized what leaders did rather than the way that they were, which stemmed from the study of psychology in the mid-1900s (Brungardt, 1996; Komives \& Dugan, 2010; Shriberg \& MacDonald, 2013). During this trajectory of developments, the common model of modern organizational leadership theory "...emerged in the 1940s, following the machine-like principles of scientific management" (Shriberg \& Macdonald, 2013, n.p.), a style of leadership based on linearity and rationality that mirrored the industrialized capitalist system in which it was applied. Later theories included transactional leadership, which asserted that workers performed better when motivated and rewarded, and situational leadership, which began to recognize the environment's impact on leadership effectiveness (Dugan \& Komives, 2011; Shriberg \& MacDonald, 2013). Arising from these dominant models of understanding and practicing leadership, which occurred within the industrial and capitalist mindset of the US in the 1900s, leadership became seen as "good management" and leaders became "good managers" (Rost, 1997).

An analysis of the fixation on "good management" further highlights the epistemology, and even ontology, behind industrial leadership (Hull, Robertson, \& Mortimer, 2018). Good management practices are characterized by "command-andcontrol structures and a strict hierarchical division of labor" (Shriberg \& Macdonald, 2013, n.p.), “emphasize productivity, [are] prescriptive in nature, and seek easy solutions for complex problems" (Dugan \& Komives, 2011, p. 37), and "assume one person in a role above others that makes decisions to direct actions towards beneficial outcomes" (Ferdig, 2007, p. 26-27). As Rost (1997) describes, these characteristics are part of the 
larger industrial paradigm typical to Western society in the 19 th and 20th centuries. This societal paradigm views organizations, people, knowledge, and even life as fragmented, hierarchical, linear, finite, understandable, controllable, and as operating within closed environments and systems (Komives \& Dugan, 2010; Rost, 1997). These views of life are based in Newtonian ways of thinking, which assume "empirical truth, reductionism, stability, certainty, predictability, and control” (Ferdig, 2007, p. 27) and mirror positivism, the dominant epistemological tradition of the 20th century. Positivism, as seen in leadership theories, supports the idea that there is one right way for one leader [manager] to lead others (Komives \& Dugan, 2010). Rost (1997) critiques this conception of leadership, stating that “...it promotes an individualistic and even a self-interested outlook on life [and] it accepts a male model of behavior and power (which has been labeled leadership style)...” (p. 9). Burns, Diamond-Vaught, and Bauman (2015) synthesize the downfalls of industrial leadership, stating that:

These common views of leadership are problematic in several ways. First, they are fragmented and specialized while the world's problems are complex and interconnected. Second, in addition to being increasingly ineffective, traditional models of leadership are disempowering, as the role of leader as authoritative expert is naturally exclusive. By defining leadership as a specific role or skill set, fewer people are likely to see themselves as capable of being leaders or making change. (p.91)

Industrial leadership, like much of Western thought, is based on separating the world into parts and from this separation, creating hierarchies that ultimately exclude participation in 
leadership. In this way, leadership theory can be seen as mirroring the problematic and oppressive epistemologies and ontologies of Western society.

Industrial, leader-centric models remain a part of the dominant leadership paradigm today and still retain influence on the perspective of leadership that is taught and practiced, including in leadership education (Ardichvili, Natt och Dag, \& Manderscheid, 2016; de Guerre and Taylor, 2004). As de Guerre and Taylor (2004) describe, "current educational contexts and pedagogical practices for leadership education are, for the most part, inspired by instrumental individualism consonant with the modern industrial context" (p. 66). This can be seen in leadership education programs that focus on skill development in individuals or that emphasize attaining goals over mutual progress (Dugan \& Komives, 2011).

Although the industrial leadership paradigm still persists, many leadership scholars have identified a shift that occurred in leadership theory, practice, and education in the mid-twentieth century (Komives \& Dugan, 2010; Komives, Dugan, Owen, Wagner, \& Slack, 2011; Rost, 1997; Shriberg \& MacDonald, 2013). This shift is attributed in part to James Burns, a leadership scholar who published his seminal book Leadership in 1978. In his book, Burns defined leadership as a political process of transformational change (Rost, 1997), which became the academic moment that "...elevated the role of the follower and shifted the focus to all people involved in the leadership process" (Komives, 2011, p. 6). This became known as transformational leadership, in which charismatic leaders transform organizations towards an ethical purpose through their visioning and interpersonal skills (Shriberg \& MacDonald, 2013). While some authors read Burns' work on transformational leadership as a paradigm shift, 
Rost (1997) actually argues that “...his conceptual model of leadership is solidly based in an industrial framework of leadership because the Burnsian notion of leadership is, at its core, about one person, a leader..." (Rost, 1997, p. 5). Nonetheless, this shift in theory towards a more collaborative leader-follower process paved the way for the paradigmatic shift away from traditional industrial leadership to contemporary leadership theories (Komives \& Dugan, 2010). Burns' transformational leadership has remained one of the dominant leadership models referenced in higher education and popular literature (Shriberg \& MacDonald, 2013).

The transition to postindustrial leadership. The paradigm shift away from industrial leadership led to a new theory and practice of leadership that Rost (1997) termed postindustrial leadership. Postindustrial leadership began to emerge in the second half of the 20th century when the world and thus organizations, particularly in Western societies, started to transition from industrial economies to more globalized, networked, and technology and knowledge-based structures of economy and society, a shift that has created the need for new ways of operating and leading (Ardichvili, Natt och Dag, \& Manderscheid, 2016; Komives, Owen, Longerbeam, Mainella, \& Osteen, 2005). Postindustrial leadership, reflecting the complex interconnections of the modern world, exemplified a change from linear, mechanistic, and positivistic leader-centric models to theories that recognize the complexity and interdependence of people, knowledge, relationships, environments, and organizations. Rather than hierarchically managing for efficiency and productivity, postindustrial leadership is characterized by transformational influence, collaborative processes, reciprocal relationships, systems approaches, complexity, authenticity, mutual development of leaders and followers, and is centered 
around principles, values, ethical actions, moral purposes, and working towards a common good (Burns, 2016; Dugan \& Komives, 2010; Komvies \& Dugan, 2010; Komives et al., 2011; Komives, et al., 2005; Rost, 1997).

Rost (1997), offering what he intended to be a truly postindustrial conceptualization of leadership, defines leadership as "an influence relationship among leaders and collaborators who intend real changes that reflect their mutual purposes" (p.11). Rost's definition includes four components: 1) the leader-collaborator relationship is noncoercive and based on influence that can go any direction, not just top-down, in an organization; 2) leaders and collaborators are the people involved in the relationship and because leadership is a relationship of influence, anyone can do leadership; 3) leaders and collaborators intend to make real change through their relationship; and 4) the intended change reflects a mutual purpose that both leaders and collaborators want. This conceptualization of leadership articulated by Rost, along with Burns' conceptualization of transformational leadership, have set the stage for many contemporary interpretations of what postindustrial leadership is and can be.

This turn from industrial to postindustrial leadership also reflected shifting epistemologies within academia and society. Komives and Dugan (2010) describe that: Naturalistic epistemological traditions such as constructivism, critical inquiry, and postmodernism as outlined by Egon Guba and Yvonne Lincoln (1994) suggest that knowledge is socially constructed, inherently subjective, complex and nonlinear, and influenced by social systems (e.g., economic, political). The use of these emergent epistemologies in leadership research and theory building contributed significantly to contemporary theories by allowing for the exploration 
of a more diverse range of perspectives, deconstructing essentialist notions of power and position, and examining nonhierarchical and nonlinear process orientations. Contemporary theories posited by Rost as reflecting the emergent or postindustrial leadership paradigm certainly reflect this perspective. (p. 112) Ways of thinking within academia began to incorporate perspectives other than those found in the dominant Newtonian and Western epistemologies, which created a change in the underlying construction of theories, including in leadership studies. Komives and Dugan go on to illustrate how these epistemologies have contributed to expanding the socially constructed notion of leadership beyond the dominant hierarchical leaderfollower conceptualization of leadership. This can be seen in the flattening of the leaderfollow relationship and how leadership has become, by this definition, a means of increasing the capacity of people working in groups together towards mutual outcomes.

Another important contribution to the understanding of the evolution of leadership that Komives and Dugan (2010) make in their article Contemporary Leadership Theories to understanding the evolution of leadership was that industrial leadership was (and still is) a model of leadership characterized by normative power differentials. Industrial leadership is based on a conception of who a leader is, which was not (and in many cases still is not) women, people of color, Indigenous people, and other marginalized groups outside of the white, settler, heteronormative male. Komives and Dugan assert that the paradigm shift to postindustrial leadership theory is underpinned by epistemologies that give voice to historically oppressed groups. Komives and Dugan (2010) describe that this: 
Revealed and validated the leadership perspectives long held by many women and those from collectivist cultures who have historically valued collaboration, interdependent relationships, community responsibility, and systemic views. The forms of leadership that these communities had been practicing were often labeled as social activism and dismissed as unsustainable and/or lacking in the organizational structure necessary for long-term outcome achievement. (p. 112) This shift in epistemology further highlights the oppressive and patriarchal nature of traditional, industrial leadership and the important move to more interconnected and relational ways of leading. Considering that many people already practiced "postindustrial leadership," Komives and Dugan go on to question whether a paradigm shift actually occurred in leadership practice, or if the theory and definition of leadership within academia and dominant society merely expanded to include those who were already engaged in postindustrial-like approaches to leadership. This would imply that a paradigm shift occurred only for those who theorized and practiced traditional leadership from dominant societal positions.

Leadership theory and practice have undergone a significant shift in the past half century as they have come to embody a less hierarchical and power-based modus operandi. While this industrial to postindustrial transition is not wholly encompassing of all leadership theory, application, and practices, as Western society is still largely based on hierarchical power structures, the change has certainly precipitated effects in the realm of leadership studies.

How is leadership developed? Along with changes in the theory of what leadership is have come shifts in the theory of how leadership can be taught or developed. 
Early leadership theories assumed that leaders were born with certain characteristics, implying that leadership could not be taught to those who did not fit within the dominant white, male model construct of what a leader is (Dugan \& Komives, 2011). Subsequent theories, such as behavioral theories, assumed that certain actions could apply to any leadership situation and that these behaviors could be learned, or acquired through training (Day, Fleenor, Atwater, Sturm, \& McKee, 2014). The complex and more nuanced theories of contemporary, postindustrial leadership, accompanied by advancing literature on adult development, have led to the field's current focus on leadership development (Komives \& Dugan, 2010). Wagner (2011) describes that "approaches to leadership... are now seen as reflective of increasing developmental capacity in the leader" (p. 85). The ability to engage in leadership is now seen, at least in part, as related to where an individual is located in a developmental process, rather than a particular trait that an individual holds or a behavior that they employ.

Since leadership development has come to be understood as occurring within the broader context of adult development, leader and leadership development have become an active subject of theory building and research (Day, et al., 2014). As Day et al. (2014) assert, understanding the process of how leadership is developed is as important as understanding what leadership is. Combining the concepts of leadership and development, Komvies, Longerbeam, Owen, Mainella, and Osteen (2006) define leadership development as a process that "involves engaging with learning opportunities in one's environment over time to build one's capacity or efficacy to engage in leadership. This developmental approach entails moving from simple to more complex dimensions of growth" (p. 402). In this way, leadership development can be seen as any 
growth that contributes to increasing one's leadership potential, including one's view of leadership, as well as leadership skills, practices, and identity (Eich, 2008).

Leadership development has become a growing and evolving field of study and practice as leadership development occurs within the rapidly changing, postindustrial, globalized and interconnected context in which organizations now exist (Ardichvili, Natt och Dag, \& Manderscheid, 2016). To gain an understanding of the state of the field, Day et al. (2014) conducted a literature review of leadership development articles published in the academic journal The Leadership Quarterly from 1989 to 2014. In their review, they describe a distinction between leader development and leadership development: "leader development focuses on developing individual leaders whereas leadership development focuses on a process of development that inherently involves multiple individuals (leaders and followers or among peers in a self-managed work team)" (Day et al., 2014, p. 64). While still overarchingly operating within an industrial leader-centric framework, Day et al. (2014) describe one of the complexities known within postindustrial models of leadership: that a distinguishing feature of leadership and leadership development is the orientation of these concepts around processes that occur between people. This highlights a growing recognition within dominant leadership studies of the value and importance of interconnected and inclusive ways of approaching leadership.

In his literature review, The Making of Leaders: A Review of the Research in Leadership Development and Education, Brungardt (1996) sought to explore how people learn to lead. Through this research, Brungardt (1996) found that leadership development occurs as a continuous lifelong process through "learning activities that are both formal and structured as well as those that are informal and unstructured... where knowledge 
and experience builds and allows for even more advanced learning and growth" (p. 83). One of Brungardt's findings was that leadership learning in adulthood can happen through people's on-the-job experiences and the situations they encounter that create possibilities to enhance their potential, which can occur when individuals stretch themselves in challenging situations. He describes two ways that people can experience leadership growth on the job: from other people, such as learning from a supervisor as an either positive or negative model or interacting with people who have different perspectives; and from work related tasks, such as changes in complex responsibilities that present opportunities for innovation. Brungardt (1996) goes on to describe that one of the most important ways to develop leadership from these on-the-job experiences is to observe and reflect on them, stating "...that the key to maximizing our leadership potential is to make the most of our experiences" (p. 86). Brungardt's findings demonstrate how leadership development is facilitated through practice and reflective learning.

Similar to Brungardt (1996), in a review and critique of leadership programs Allio (2005) further highlights the idea that leadership cannot be taught per se, rather it is learned through experience. He proposes that experience and practice are of paramount importance for developing leadership, stating that "leadership is a potentiality, inchoate and unrealized until it is developed" (Allio, 2005, p. 1073). His critique of leadership programs rests on the fact that leadership programs often only bring leaders into potentiality, relying mainly on cognitive development by teaching aspiring leaders about leadership theories. He argues that this form of leadership education is insufficient in actually teaching people how to engage in leadership behaviors, asserting that leadership 
competence derives from experience through experimentation, trial and error, repeated and dedicated practice, and coming up against transformational challenges. Allio further describes strategies that can be employed when attempting to assist others in developing their leadership, including learning of knowledge through cognitive study and selfknowledge through reflection and feedback, as well as creating learning challenges and providing mentoring. Hodgkinson (as cited in Komives, Lucas, \& McMahon, 2013, p. 93) wrote, “...the very nature of leadership is that of practical philosophy, philosophy-inaction," highlighting the fundamental praxis orientation of leadership as a concept.

Summary. Leadership is a complex and multifaceted term that has many different meanings in both academia and Western society. The theoretical evolution of leadership studies has in part shifted from Newtonian and Western ways of thinking and being, the paradigm of industrial leadership, to the paradigm of postindustrial leadership, which is based on constructivist epistemologies. With these theoretical evolutions have come changes in the way leadership is practiced, from leading being concomitant with power structures, hierarchy, and good management, to leadership based on collaboration, relationality, and how people practice leadership with each other. With the growing recognition that leadership is something that all people can engage in together, emphasis has been placed on how people can develop leadership capacities. Within the growing realm of leadership development studies, an important component of the theory and practice of leadership development is that of application, as many scholars believe that leadership cannot necessarily be taught, it must be learned through practice and reflection on lived experience.

\section{How is Leadership Cultivated in Students in Higher Education?}


During the evolution of leadership and leadership development, scholars began to explore these phenomena for specific groups of people. One of these groups that has spawned its own sub-field of literature is students in higher education. This section will describe the emergence of student leadership as a field of study and practice, summarize common models of student leadership and theories of student leadership development, and synthesize perspectives on specific pedagogies and strategies for encouraging this development.

The emergence of student leadership. Following the publication of Burns' book Leadership in 1978, leadership educators in higher education began to adopt and use the Burnsian transformational and ethical approach to leadership (Komives, 2011). After a decade of scholarship within the emerging postindustrial leadership paradigm, Kouzes and Posner published their book The Leadership Challenge in 1987, which outlined a framework for leadership that was seen as applicable to leadership education practices in higher education; this publication and its accompanying survey instrument were later adapted for use with college students (Komives, 2011). However, it was not until the 1990s that models specific to student leadership in higher education emerged. Two seminal student leadership models were published in that decade: the Social Change Model of Leadership Development and the Relational Model of Leadership (Dugan \& Komives, 2011). These models became known as "emerging models" because of their emphasis on reciprocity and relationships in the leadership process (Komives, 2011). These approaches to leadership fit within the postindustrial paradigm of leadership, which some leadership educators view as the most appropriate approach for college students, as postindustrial leadership is more suited than industrial leadership to the 
knowledge-based, networked world we live in that requires people to collaborate with each other to enact change (Komives et al, 2005).

Since becoming a subfield of leadership studies, research has shown a significant relationship between higher education and increasing leadership capacities of students (Dugan \& Komives, 2010). Leadership is often portrayed as a primary purpose of institutions of higher education (Brungardt, 1996; Eich, 2008) and leadership is sometimes framed as a byproduct of participating in higher education (Dugan \& Komives, 2011). However, because there are many factors to consider when attempting to encourage student leadership development in higher education, it is necessary to support intentional actions that help foster this development (Dugan \& Komives, 2011).

Student leadership models. One of the first leadership models that was widely applied to the student context was servant leadership, generated by Robert Greenleaf in the 1970s alongside Burns' transformational leadership (Komives \& Dugan, 2010). Servant leadership sought to shift the role of positional leaders from being authoritative and directive to being supportive of and engaging with others, asking the question "...of whether people were better off for having worked together toward some shared outcome" (Komives et al., 2011, p.43). Servant leadership can be thought of as a theoretical bridge between industrial and postindustrial leadership because although it is leader-centric, it focuses on a values-based shared process that leads towards mutual outcomes. This model's focus on the benefits of people working together, while still operating from within the industrial leader-centric paradigm, was instrumental in the development of the scholarship and practices of postindustrial leadership, including collegiate specific leadership theories (Komives \& Dugan, 2010). 
One of the first cited college student specific models, the Relational Leadership Model, was published by Komives, Lucas, and McMahon in 1998 (Komives, 2011). The authors, grounding their model in the epistemologies of the postindustrial paradigm, define leadership as "a relational and ethical process of people together attempting to accomplish positive change” (Komvies, Lucas, \& McMahon, 2013, p. 95). Relational leadership is comprised of five components: purposefulness, inclusiveness, empowerment, ethical practices, and a process orientation; these amalgamate into an "approach to leadership [that] is purposeful and builds commitment toward positive purposes that are inclusive of people and diverse points of view, empowers those involved, is ethical, and recognizes that all four of these elements are accomplished by being process-oriented" (Komives, Lucas, \& McMahon, 2013, p. 95). The authors further describe the process, or the how, of engaging in relational leadership as being enabled by knowledge, being aware of the self and others, and acting, or knowing, being, and doing. These three components of the process of leadership interact: the knowledge we possess (knowing) and our beliefs and the way we are in the world (being) influence how we think, which can influence how people act and behave (doing). Relational leadership is an example of postindustrial leadership applied to the collegiate context that has been used in campus leadership programs and continues to influence theoretical developments in student leadership literature.

The other common model, the Social Change Model of Leadership (SCM), has become the most widely applied model of student leadership in higher education programs aimed at developing socially responsible leaders (Komives \& Dugan, 2010). This model was developed specifically for students in higher education by a group of 
student leadership professionals who came together to collectively discuss “.... what knowledge, values, or skills students need to develop in college in order to participate in effective leadership focused on social change" (Wagner, 2007, p. 8). The SCM, aligning with the values of the postindustrial paradigm, views leadership as a nonhierarchical, collaborative, and purposeful process based on socially responsible values that is meant to increase students' capacity to work with others (Wagner, 2007).

As described by Wagner (2007) in an overview of the SCM, the model is comprised of seven critical values, also known as the Seven C's, that are categorized into individual, group, and community values. The individual values include: Consciousness of Self, the self-awareness of what beliefs motivate people to act, as well as awareness of one's state of being in a given moment; Congruence, acting consistently with one's values and beliefs; and Commitment, having significant investment and energy in a group and its goal. The group values are: Collaboration, working together with others by engaging diverse perspectives; Common Purpose, having shared aims and values and creating a shared vision; and Controversy with Civility, the acknowledgement that differences in views will arise and that these differences can be aired openly but civilly. The community values are comprised of Citizenship, which is defined as holding the belief that people are part of interdependent communities and have the responsibility to become reciprocally engaged in society with others. Komives and Dugan (2010) further describe the function of Seven C's:

The individual values identify aspects of the self that are central to working in socially responsible ways for change.... The group values identify important practices that are central to groups of diverse people working toward common 
goals... The societal-community value of citizenship brings the frame of a heightened responsibility to improve our shared world acting as an active citizen in all one's communities of practice. (p. 115-116)

While distinct, the levels of Seven C's influence and interact with one another in feedback loops, as growth in one level can lead to growth in another (Wagner, 2007). Because the SCM was designed specifically for college students, it has been widely influential in leadership education programs (Wagner, 2007). Figure 1 depicts the SCM model.

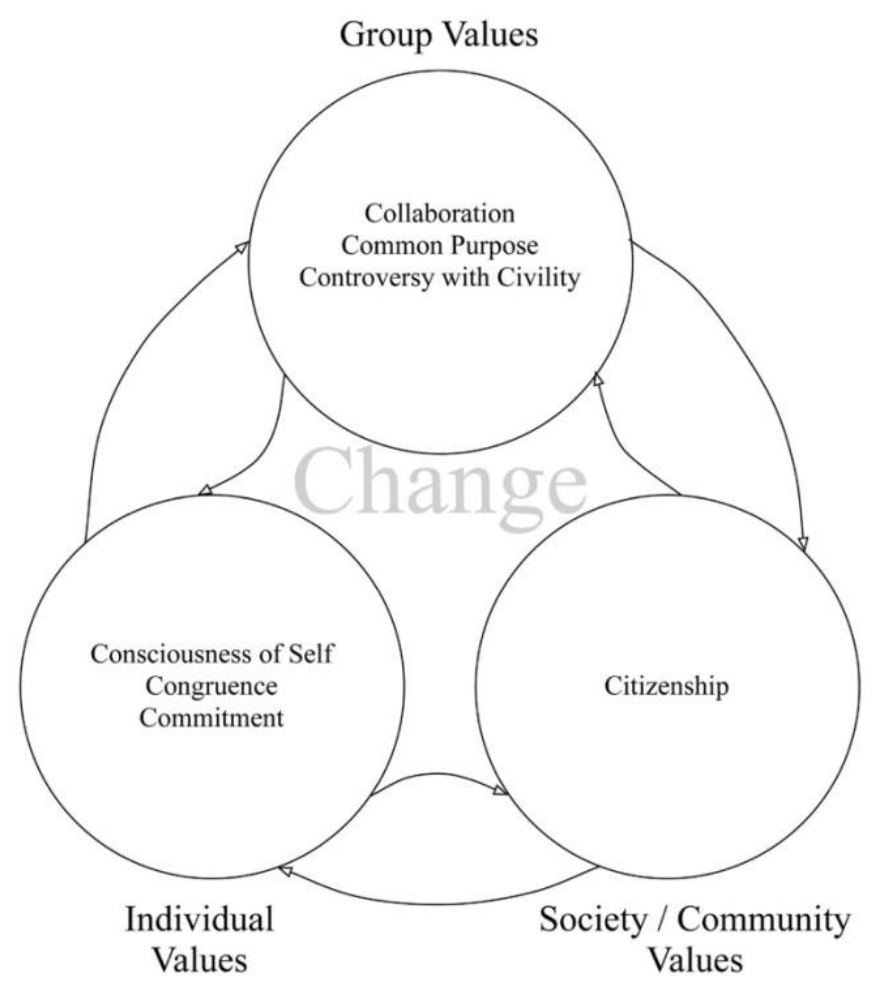

Figure 1. The Social Change Model of Leadership Development (Wagner, 2007).

Student leadership models have emerged in recent decades with the intent of fostering the development of student leaders in higher education. These models are based in the postindustrial leadership paradigm and emphasize people working together towards 
social change. While these models provide useful frameworks for understanding and encouraging student leadership, there are many other factors that can influence students' leadership development as well.

Cognitive, identity, and self-efficacy development. Along with the trend in broader leadership studies, recent scholarship has focused on student leadership development and learning, or how students can learn to practice leadership over time. In her chapter in the Handbook for Student Leadership Development, Wagner (2011) provides an overview of the concept of development as it relates to student leadership. She defines development as a process of "...increasing complexity in terms of reasoning, values, and integration of multiple identities... [that] reflects a qualitatively different state of being, not just having more of the same kind of knowledge" (Wagner, 2011, p. 86). As with the broader field of leadership development, applying this understanding of development to student leadership allows us to understand that a student's stage of development will impact their understanding, learning, and application of leadership theories and practices. Having an understanding of developmental processes is important because it can allow leadership educators to create learning experiences that provide the optimal levels of challenge and support for students to move into more complex conceptualizations and practices of leadership (Wagner, 2011).

Because student leadership development itself is a relatively new field of study, scholars have looked to theories on adult and student development to inform an understanding of this phenomenon (Wagner, 2011). In the Handbook for Student Leadership Development, Wagner (2011) reviews a variety of developmental theories in relation to student leadership development. In one example, Wagner discusses the way 
cognitive development theories, which are generally used to describe how students make meaning of their experiences and develop intellectually and morally, can help to understand and encourage leadership development. These theories, such as Perry's Cognitive Development Theory and Kegan and Lahey's Plateaus in Mental Complexity, involve stages or levels of increasing complexity that students pass through, which can be applied to students to understand their current views on leadership (Wagner, 2011). When applied to leadership, these cognitive levels or stages can help shed light on how students move from viewing leadership as a simple leader-follower relationship to more complex ways of making meaning and understanding leadership that recognize interdependence with others.

Another theory that is often used in relation to student leadership development is Chickering's theory on identity establishment, a psychosocial theory of student development that focuses on the psychological and social development of college students (as cited in Komives et al., 2009). In Chickering's theory, students develop through vectors (stages) of being in relationship with themselves and others that eventually lead students to establish their own sense of identity, or “...a clear, comfortable, and secure sense of self" (Komives et al., 2009, p. 22). Identity development is an important consideration within leadership development because it provides an understanding of how students come to see themselves as leaders.

Combining the definition of identity development, in which individuals come to hold an enduring sense of self, with leadership creates a definition of leadership identity as "....a sense of whom [individuals] are as leaders and how they make meaning of involvement in groups through various roles" (Wagner, 2011, p. 95). Leadership identity 
development is thus how leadership is learned, developed, and becomes integrated into one's sense of self over time. Leadership identity development also includes the aspect of salience, or how integral a leadership identity is to someone, which can predict if someone will seek out opportunities to develop leadership competence (Wagner, 2011). Leadership identity and its salience develop over time by having leadership experiences and integrating these experiences into one's identity, as well as through developing selfawareness, the ability to be conscious of one's characteristics and behaviors within moments (Wagner, 2011). Leadership identity development thus is both about developing an identity as a leader through experience as well as being aware of oneself as a leader through reflection.

To better understand the important process of how students build their leadership identity over time, Komives et al. (2005) developed the leadership identity model (LID). The LID, which is now being applied by some campuses to design leadership learning activities (Komives et al., 2009), was developed from a grounded theory study that involved thirteen students who had been observed working effectively with others towards mutual purposes, thus exhibiting the theoretical dimensions of the Relational Leadership Model (Komives et al., 2005). The research found that the students progressed through six identity stages that increased in complexity over time from a leader-centric perception to seeing leadership as a collaborative, relational process. This progression through the stages was influenced by changes in categories that impacted development; the categories found were the "developing self, which interacted with group influences to shape the student's changing view of self with others. This changing view of self in relation to others shaped the student's broadening view of what leadership 
is and created a leadership identity" (Komives et al., 2005, p. 596), all of which are framed by developmental influences. An essential aspect of experiencing change within the categories is an individual's expanding self-awareness of their identities (Komives et al., 2006). In particular, the students exhibited a relational leadership identity, which "appears to be a sense of self as one who believes that groups are comprised of interdependent members who do leadership together" (Komives et al., 2005, p. 608). Although their study was not meant to be generalizable, the LID model provides an important understanding of how student leadership development can occur in the relational, postindustrial paradigm as it identified conditions and processes that can foster students coming to understand themselves as relational leaders (Komives et al., 2005).

In addition to leadership identity development, another important consideration in student leadership development is self-efficacy. Self-efficacy, a concept published by Bandura in 1997, is defined as "the belief in one's ability to accomplish a challenging task in a particular situation" (Wagner, 2011, p. 92). When related to student leadership, self-efficacy can be thought of as a student's belief in their ability to enact their leadership capabilities in a given situation (Komives et al., 2009). In other words, students who believe in their capacity to engage in leadership are more likely to enact their leadership capacity in new and challenging situations. Building and developing efficacy is thus an important part of leadership development and can be enhanced alongside leadership identity development (Komives et al., 2009). Bandura (as cited in Komives et al., 2009) outlines ways in which self-efficacy can be enhanced, which can be used to design effective leadership development programs and environments: mastery experiences, vicarious experience, verbal persuasion, and assessment of physiological 
and affective states. When applied to a leadership context, these strategies could be: participation in and reflection on leadership experiences that can help build skills to be taken into other situations (mastery); observation of others successfully performing challenging tasks and modeling effective leadership (vicarious); receiving significant affirmation of one's capacity and sponsorship (verbal persuasion); and attending to physical and emotional states (Wagner, 2011). Self-efficacy is an important consideration in supporting the complex process of leadership development as increased leadership self-efficacy can contribute to students taking on more challenging leadership experiences, which will in turn support their growth in their leadership capacities.

There are many considerations when trying to support student leadership development, including cognitive, leadership identity, and self-efficacy development. When applied to leadership, these perspectives on development can help practitioners support students in increasing their leadership capacities. Cognitive development can help students to understand the complexities of relational leadership, leadership identity development can help students to integrate leadership into who they are, and self-efficacy can help students to believe in themselves as leaders. Developing students that have complex understandings and practices of leadership is important within the postindustrial, relational paradigm of leadership, as leadership within this paradigm is inherently about coming to know, understand, and be able to operate as one's self within interconnected webs of influence and relationships with others.

How to: strategies that support student leadership development. As has been described, there are many factors that can contribute to a student's path towards becoming a relational leader. Along with research on how leadership develops, scholars 
and practitioners have studied specific strategies that can be implemented when designing programs to support student leadership development.

In the Handbook for Student Leadership Development, Meixner and Rosch (2011) provide a chapter on "powerful pedagogies” (p. 310), or effective instruction, management techniques, and program design that leadership educators can employ to design effective leadership learning experiences in their programs. These pedagogies include experiential learning, team-based learning, peer education, sociocultural discussion, service-learning, mentoring and advising, and contemplative practice.

The first pedagogy Meixner and Rosch (2011) describe, experiential learning, is the concept that learners integrate knowledge most effectively when actively engaged in their education by applying and testing their knowledge to their environments. This is especially important for leadership education, as leadership is developed through learning-by-doing (Allio, 2005). The second pedagogy is team-based learning, another important tool for educators wishing to cultivate the postindustrial relational models of leadership in their students. Incorporating team-based learning into programs or courses goes beyond group work, as team-based learning is characterized by students working in "high-performing interdependent teams" (Meixner and Rosch, 2011, p. 319) in which students learn to apply each of their unique skills to solving problems together over time. Peer education, the third pedagogy, recognizes that development occurs for both students and student educators in settings and programs where peers "assist, coach, role model, tutor, and support" others (Meixner \& Rosch, 2011, p. 321). The fourth pedagogy is sociocultural discussion, which can be thought of as "the ability to share one's perspectives on issues of importance while listening to the viewpoints of others... [and] a 
nuanced and complex view of a situation, an understanding of competing priorities, and an ability to find links between disparate perspectives..." (Meixner \& Rosch, 2011, p. 322). The capacity to engage in effective sociocultural discussion, which is understood to be highly important to leadership abilities, may be gained in settings where students come together to have discussions over topics of difference or where students from diverse backgrounds discuss matters of importance to them. Service-learning is the fifth pedagogy that can result in increased leadership abilities. Service-learning involves wellstructured opportunities for students to apply their learning to meet the needs of an external community and to engage with and reflect on that experience. The sixth pedagogy, mentoring and advising, or a mutual relationship aimed at helping or advising a mentee to achieve learning goals, is considered to be an important tool through which students can make meaning of their experiences. The final pedagogy they describe is contemplative practice, or the integrated and holistic learning that students experience when they have the opportunity to unite their bodies, minds, and spirits through activities like meditation or group reflection. These kinds of activities are becoming more commonly used in higher education and are thought to be able to help students "develop their leadership skills, cultivate self-awareness and humility, and co-exist in a rapidly changing, uncertain world" (Meixner \& Rosch, 2011, p. 327).

While the pedagogies described are often only theoretically linked to leadership development (Meixner \& Rosch, 2011), some empirical research has been done into the pedagogies, teaching strategies, and program design that can support student leadership development. In 2010, Dugan and Komives published a study that explored factors that influenced students' socially responsible leadership capacities. This quantitative study 
analyzed the responses of over 14,000 students in colleges across the United States using a survey tool that measured values associated with the Social Change Model (SCM) and leadership self-efficacy. Results from this study indicated that three variables had a significant influence on socially responsible leadership development in students: faculty interaction and mentoring, involvement with community service, and socio-cultural conversations. This study, as well as prior research, has confirmed that meaningful relationships with faculty can help shape student leadership and that practitioners might enhance leadership development by encouraging these relationships. A second variable was involvement with community service, which had a positive influence on the development of most of the SCM leadership outcomes, indicating that practitioners should continue to employ the intentional use of community service and reflection in their program design. The final variable, the level of student engagement in socio-cultural conversations, was the most influential factor found in their data. Dugan and Komives' (2010) findings:

Suggest that peer conversations, not just interactions, across a wide array of differences (e.g., social issues, lifestyles, personal values, political ideologies, and multicultural concerns) can contribute to gains in theoretically grounded measures of socially responsible leadership. The importance of peer conversations about difference cannot be understated, and educators are encouraged to actively structure and foster such opportunities throughout leadership curriculum and cocurriculum. This serves as a reminder that conversations about diversity and difference should not be compartmentalized to an insular segment of a leadership 
program as they often are (Segar, Hershey, \& Dugan, 2008), but integrated throughout leadership curricula. (p. 539)

Discussing difference with peers has been shown to be an important contributor to students' relational leadership abilities and thus should be an integral part of any leadership development program. This finding on the importance of socio-cultural conversations reflects the emphasis on this leadership development strategy found in the literature (Dugan \& Komives, 2010).

In addition to the three variables that support student leadership development (faculty interaction and mentoring, involvement with community service, and sociocultural conversations), Dugan and Komives (2010) discovered two important overarching themes in their study. The first theme was that students mainly experienced development in the "group" and "societal" values of the SCM, and less so in the "self" values. They state that this is could be seen as an unsurprising finding, as collegiate experiences are often dedicated to expanding a student's sense of self in relation to others and, because leadership is inherently a group process, participating in group experiences in college would affect the group and societal values. The other theme from their findings relates to the role of formal leadership programs. They found that participation in short or medium duration leadership programs significantly enhanced capacities in some of the measures compared to students who did not participate in a formal program, while the opposite was true for students who participated in long term leadership programs. They speculate that the nature of some long-term programs might differ from socially responsible leadership in their intended outcomes, or that students who participate in these programs might hold hierarchical or positional leadership philosophies. 
Another concept Dugan and Komives (2010) intended to explore in their study was the effect that students' level of leadership self-efficacy had on their leadership development. They found that a student's level of leadership self-efficacy impacted leadership development measures, indicating that self-efficacy has a strong influence on the leadership development process. They suggest that “...it may be just as important to cultivate student efficacy for leadership as it is to engage in direct capacity building” (Dugan \& Komives, 2010, p. 541). This indicates that designing higher education experiences that increase both leadership capabilities as well as self-efficacy can holistically influence student leadership development.

In another study, Eich (2008) sought to identify attributes of successful programs that contributed to student leadership development. This grounded theory study consisted of 62 interviews with program stakeholders, including students, administrators, teachers, alumni, and student staff, from a varied set of undergraduate leadership programs that educate students in relational models of leadership. The study identified 16 different programmatic attributes that contribute to student leadership development, that were then categorized into three different clusters.

The first cluster, Participants Engaged in Building and Sustaining a Learning Community, "speaks to the vital role that the individuals who are a part of the programs play in helping each other to develop as better leaders" (Eich, 2008, p. 180). The program attributes in this cluster are: Diverse and Engaged Students; Experienced and Committed Practitioners; Educators Model Leadership and Support; Participants Unite Through Small Groups; Participants Foster a Culture of Challenge and Support; and Participants Cultivate One-on-One Relationships. These all contribute to the second cluster, Student 
Centered Experiential Learning Experiences, which relates to "what was done in the program to help students develop as leaders" (Eich, 2008, p. 182) and includes: Students Practice Leadership Individually and Collectively; Students Engage in Reflection Activities; Students Apply Leadership Concepts to Themselves in Meetings; Students Encounter Episodes of Difference; Students Engage in Service; and Students Engage in Self-Discovery Through Retreats. The attributes of the third cluster, Research-Grounded Continuous Program Development, which contribute to student leadership development are: Flexible Program Design to Accommodate Student Interests; Content Anchored in Modeled Leadership Values; and Systems Thinking Applied for Constant Program Improvement. Each attribute was further organized into actions that enact that attribute and student outcomes that were enhanced by the attribute, contributing a readily applicable theory for high-quality leadership development programs. In a synthesis of his findings, Eich (2008) writes that:

High-quality programs actually practice the kind of inclusive, empowering, purposeful, ethical, and process-oriented leadership for positive change that they advocate to their students. This practice is reflected through all of the clusters of the theory from the engagement of the participants, to the student-centered learning experiences of the program, to the continuous research-grounded program development. It is a "lived leadership" that is reflected throughout the teaching and pedagogy of the program. Students learn about leadership in the process of understanding themselves, others, and the world around them. The factors that facilitate this learning include the participatory students themselves, the environment in which they learn, the activities they do, and the systems 
approach of the program that leads to improvement. Put another way, high-quality programs are spaces that help students do leadership and understand what they are doing along with others. In creating a space for this to happen, leadership programs that integrate and enact attributes of this theory demonstrate not only that leadership can be taught and learned but that leadership development can be fostered and accelerated as a result of a program educational intervention rather than leaving leadership development to chance through life experiences. (p.186) For student leadership development programs to be effective, they must embody the type of leadership they seek to help their students develop. Within the postindustrial, relational understanding of leadership, this means teaching students to do leadership with others through experiential pedagogies that reflect this view of leadership. Eich's synthesis highlights that leadership praxis, as leadership can be thought of as philosophy-in-action (Hodgkinson as cited in Komives, Lucas, \& McMahon, 2013), is not only for individuals learning about and practicing leadership but for programs as well, which must apply the leadership philosophies they hold through their educational practices.

Summary. As with leadership development, student leadership development in higher education is a complex process. Emerging from the postindustrial paradigm of leadership, student leadership theories and models deal with the relationality and interconnectedness of people engaging in a process of doing leadership and creating change together. Theories of adult and student development, such as cognitive, identity, and self-efficacy development, have contributed to understanding how students can increase their capacity to engage in the complex process of relational leadership. For leadership programs to do this effectively, they must use pedagogies and practices that 
reflect the postindustrial, relational philosophy, encouraging students to learn about themselves and how they can work with others. The next section will explore another iteration of leadership studies: sustainability leadership.

\section{Sustainability Leadership}

In addition to student leadership, sustainability leadership has emerged as another field of inquiry related to the study of leadership. This section will examine the origins of sustainability leadership, discuss what differentiates sustainability leadership from normative leadership, describe distinguishing characteristics of sustainability leadership, and review research on developing sustainability leadership in higher education, beginning with an exploration of the history of sustainability leadership.

History and development of sustainability leadership. The history of sustainability leadership can be examined in relation to the evolution of leadership theories and practices. In his piece on sustainability leadership in the 21 st century, Shriberg (2012) traces the modern history of leadership, infusing this narrative with perspectives from the environmental and sustainability movements and placing sustainability leadership within, and yet apart from, this evolution. He discusses the rise of industrial leadership, which Shriberg terms transactional or machine-oriented leadership, in the industrial and post-WWII eras specifically in relationship to land and the environment. He asserts that industrial leadership theories and practices “....arose in a time of plenty, when resource constraints and social justice were sidebars.... in a world where environmental problems were isolated and local, where there was always another frontier for resources extraction (figuratively or literally)...." (Shriberg, 2012, p. 474). Settler environmental leadership began to emerge in the US in the 1960s and 1970s in 
part as a response to the environmental issues, and the mindsets that created the conditions for them to arise, that were becoming apparent to an increasing amount of people at that time. Shriberg (2012) argues that this form of leadership was a critique of the capitalist and consumeristic trends in dominant society, stating that environmental leaders relied on "grassroots activism and popular support to propel agendas" (p. 469), and even going so far as to argue that environmental leadership was often enacted in opposition to the very corporate culture and capitalist structures from which industrial leadership theories and practices originated.

A subsequent development in the trajectory of this type of leadership was the evolution of ecological leadership, a form of leadership which is "based in the study of ecology and on the emergence of the environmental movement" (Shriberg, 2012, p. 475). Shriberg (2012) describes that ecological leadership derives its theory from the metaphor of organizational systems as ecological systems, which are complex, interconnected, and oriented around the role of relationships, mirroring postindustrial leadership values and sitting apart from the characteristics of mechanistic, industrial leadership. Shriberg contends that the environmental movement of the 1960s and 1970s actually employed the principles of ecological leadership. The emergence of ecological leadership can be seen as part of the shift from environmental, and even traditional, leadership towards sustainability leadership. However, even though environmental leadership began with a critique of dominant society, it "has traditionally focused on ecological and environmental issues, ignoring the larger questions of social and economic justice and equity that a sustainability-oriented perspective raises" (MacDonald \& Shriberg, 2016, p. 361). Incorporating the holistic perspective of sustainability with ecological leadership 
processes has allowed for the shift from environmental leadership to sustainability leadership to occur, which includes a broadening of the content that leadership encompasses as well as a departure from hierarchical, leader-centric (whether transactional or transformational) models of leadership (Shriberg, 2012). In this way, sustainability leadership can be seen not necessarily as arising from but rising apart from and in opposition to dominant industrial leadership theories, while paralleling and augmenting postindustrial relational models of leadership with the sustainability perspective. This differentiation of sustainability leadership causes sustainability leadership to embody distinct qualities, orientations, and purposes from normative and student leadership theories.

What differentiates sustainability leadership? As discussed, sustainability leadership holds a unique position within and beyond the evolution, theories, and practice of normative leadership. One of the most important distinctions between leadership and sustainability leadership theories is the orientation of sustainability leadership towards solving [un]sustainability issues. The challenges that the world faces today, as well as the difficulty in defining these challenges and developing solutions for them, requires leadership that is better equipped to handle complexity and interrelatedness than the epistemological underpinning, theories, and practices of industrial leadership (Burns, 2016; Hull, Robertson, \& Mortimer, 2018; MacDonald \& Shriberg, 2016; Shriberg, 2012; Shriberg \& MacDonald, 2013). In her seminal piece Sustainability Leadership: Cocreating a Sustainable Future, Mary Ferdig (2007) defines an understanding of what sustainability leadership attempts to address: 
Three critical and interrelated areas that require our thoughtful attention if we are to move toward a more sustainable future: (1) long-term viability of natural systems and the services they provide for human existence; (2) unacceptable social conditions at home and in communities around the world; and (3) local and global economies and the potential they hold to create a modicum of wealth and prosperity for all inhabitants of the earth. The challenges represented in these three interconnected areas require us to rethink the nature of leadership. (p. 26) Here, Ferdig uses the framework of the three pillars of sustainability to outline the complex challenges that sustainability leadership is oriented towards. While leadership and student leadership studies are often intended to enable individuals and organizations to perform or manage better or to work with others towards social change, sustainability leadership deals specifically with how leadership and leaders can be equipped to address these complex global challenges.

Like leadership, and in some ways even more so because of its relative academic infancy and the complex subjects it deals with, sustainability leadership is a nebulous concept with an array of sometimes conflicting definitions, applications, and theories of practice. In one attempt to develop a theory and definition of sustainability leadership, Visser and Courtice (2011) interviewed business leaders that had in some capacity exhibited a form of sustainability leadership in their companies. From their study they developed a conceptualization of sustainability leadership that defines "a sustainability leader [as] someone who inspires and supports action towards a better world" (Visser \& Courtice, 2011, p. 2), a definition which they assert is ultimately about creating change. In their view, leadership for sustainability "is not a separate school of leadership, but a 
particular blend of leadership characteristics applied within a definitive context" (Visser \& Courtice, 2011, p. 3). This idea of sustainability leadership begs examination, as the way it was developed (interviewing CEOs in an organizational setting) fits within the industrial leadership paradigm, which has been argued is incongruous with sustainability leadership.

While some scholars, such as Visser and Courtice (2011), see the theory and practice of sustainability leadership as applying sustainability to normative leadership theory, content, and contexts, many sustainability leadership scholars view sustainability leadership as a departure from traditional leadership theory entirely (Bendell \& Little, 2015; Burns, Diamond-Vaught, \& Bauman, 2015; Ferdig, 2007; Shriberg \& MacDonald, 2013). Because sustainability leadership is a response to complex and interconnected unsustainability issues, it goes beyond the characteristics of traditional leadership and, as Ferdig (2007) describes:

It represents a radically expanded understanding of leadership that includes an enlarged base of everyday leaders in all walks of life who take up power and engage in actions with others to make a sustainable difference in organizations and communities. This requires leaders to see themselves in relationships within a broad human dynamic of collaborative experience in spite of, or in the absence of, formal positions of power in order to build synergy and momentum needed to cocreate pragmatic responses to complex challenges. (p. 33)

This radical expansion of the conceptualization of leadership, as Burns, DiamondVaught, and Bauman (2015) describe, involves much more "than simply applying a new lens of leadership to business as usual" (p. 89), rather "sustainability leaders recognize 
and critique the root causes of unsustainability, seek to understand the social, cultural, economic, and ecological impacts of their work, and acknowledge and value the ecological and cultural diversity of natural systems" (p.89). Shriberg and MacDonald (2013) further describe this idea, stating that "the concept of sustainability embodies a different, more integrative approach to leadership.... leadership for sustainability is more than the application of traditional leadership theory and environmental leadership to sustainability" (n.p.). This expansion of sustainability leadership applies to leadership education as well because transformational leadership theories, while based on people working together around a higher ethical purpose and shared goals, are still situated within the industrial leadership paradigm and are fundamentally incompatible with the relationality and nonhierarchical qualities of postindustrial leadership (Shriberg, 2012). The leader-centric and power-based models of transformational and traditional leadership, which are commonly taught in leadership education, are not "oriented to tackle the complex realities embodied in environmental and interrelated social and economic issues" (MacDonald \& Shriberg, 2016, p. 361). Sustainability leadership and sustainability leadership education go beyond and even exist apart from traditional leadership in both content and process.

In their article Seeking Sustainability Leadership, Bendell and Little (2015) offer an in-depth critique of the perspective that sustainability can be simply applied to leadership theory. They argue that prefixing leadership with sustainability often leads to a practice of leadership that focuses on outcomes related to sustainability challenges, such as sustainable development goals or increased resilience in dealing with ecological disasters. Instead, they believe that sustainability leadership must account for ethics and 
values in how people engage in the process of doing leadership. Their definition of sustainability leadership accounts for this behavioral component: "sustainability leadership is any ethical behavior that has the intention and effect of helping groups of people achieve environmental or social outcomes that we assess as significant and that they would not have otherwise achieved" (Bendell \& Little, 2015, p. 16). Another important component of their definition is the postindustrial focus on groups of people engaging in leadership. This focus on leadership as shared process between people is integral to Bendell and Little's argument that sustainability leadership must be a collective effort, rather than the outcomes of well-intentioned individuals applying themselves to solve sustainability challenges. They assert that we should "consider leadership as something shared, an episodic social process for participation in which we can all become competent" (Bendell \& Little, 2015, p. 20), highlighting that leadership development is also a process that anyone can engage in. Bendell \& Little further draw a connection between industrial leadership and sustainability issues, citing the theories and education practices that center around exceptional individual leaders as evidence of the Western industrial mindset that seeks to "control, rather than liberate, normal people and nature.... that is causing us to alienate ourselves from nature and each other, and therefore is a mind-set at the root of unsustainability" (Bendell \& Little, 2015, p. 19). They advise caution in applying industrial leadership theories, even transformational leadership, to sustainability issues without taking a critical perspective to those approaches.

In addition to the orientation of sustainability leadership towards issues of sustainability, sustainability leadership also serves a radically different purpose than traditional, industrial leadership. In her exploration on the purpose of sustainability 
leadership, Evans (2018) defines a continuum of leadership characteristics that includes sustainable leadership on one side and exploitive (traditional) leadership on the other. She writes that the difference "between exploitive leadership and sustainable leadership is one that hinges on the purposes to which leadership is applied" (Evans, 2018, p. 67). Traditional leadership, which mirrors Western colonial society, encourages exploitation, collective violence, and power dynamics that seek to uphold the "leader's" positional power status. While a critical examination of sustainability leadership might suggest otherwise, she asserts that sustainable leadership resides on the other side of this continuum, with the purpose of sustainable leadership being to foster the long-term health, integrity, and resiliency of socio-ecological systems.

As demonstrated by these sustainability scholars, sustainability and normative conceptualizations of leadership are related and yet radically separate in their orientations and purposes. Sustainability can be used as a framework to guide leadership, as leadership in the modern age needs to account for sustainability challenges (Shriberg, 2012). And sustainability efforts can be augmented by leadership, as leadership is about motivating people to work together to enact change (Burns, 2016). Bendell and Little (2015) eloquently describe the purpose of sustainability leadership another way:

It is about moving from a leadership as desperate heroes to divine hosts. We use the word divine, as ultimately a discussion of leadership becomes one of purpose, which makes it an issue involving the deepest questions facing us, the meaning of our lives, our species, and the cosmic plan or comic fluke we call planet Earth. (p. 22) 
Sustainability leadership ultimately grapples with the task of creating a better world. As it is both connected to and separate from normative leadership theories, a distinct set of characteristics of sustainability leaders and leadership practices exists.

Characteristics of sustainability leaders and leadership. Because of its specific orientation towards sustainability challenges and because it requires a new idea of leadership, sustainability leadership and leaders are distinguished by a specific set of characteristics that differ from normative leadership and leaders. This section will explore what sustainability leadership scholars identify as important characteristics of sustainability leadership and leaders.

In order to describe what sustainability leaders are, Ferdig (2007) provides an indepth description of the foundations of sustainability leadership. She writes against the Newtonian, mechanistic industrial leadership paradigm, citing emerging understandings within complexity sciences as a new way to view leadership. Ferdig (2007) highlights three key tenets of this new view of leadership: anyone can be a leader in any place they choose to foster sustainable conditions; the role of a leader hinges on being able to lead 'with' instead of 'over' others; and leaders operate within the holistic interconnections among and between people and natural systems. Within this view of leadership, Ferdig (2007) writes that sustainability leaders are seen as people who "create opportunities for people to come together and generate their own answers" (p. 31) by taking conscious actions grounded in ethics that reach beyond self-interest to support healthy economic, environmental, and social systems.

In their article Leadership for Sustainability: Theoretical Foundations and Pedagogical Practices that Foster Change, Burns, Diamond-Vaught, and Bauman (2015) 
further expand the notion of sustainability leadership by exploring the intersection of leadership, leadership development, and sustainability education literature and theory. Through this exploration they identified three elements that characterize sustainability leadership. The first element, understanding leadership as a way of being and acting that is embedded in sustainability values, highlights the importance of acting from relational values of interconnection with land and other beings. They further expand on the idea of sustainability leadership as a value-laden way of acting, stating that "leadership thus reflects values in action; acting from one's values to address complex sustainability challenges and to affect sustainable change" (Burns, Diamond-Vaught, \& Bauman, 2015, p. 90). The second element they identified is that "leadership for sustainability is rooted in a living processes paradigm" (Burns, Diamond-Vaught, \& Bauman, 2015, p. 90), which also relates to a shift in ways of being and knowing. A living processes paradigm reflects the postindustrial leadership epistemology and ontology, in which the complexity and interconnections life and organizations is recognized, however the second element grounds this perspective in the living processes of the human and nonhuman world. In order to function within a values-based living processes paradigm, Burns, DiamondVaught, and Bauman articulate the third element as sustainability leadership is an inclusive, collaborative, and reflective process. In contrast to traditional leadership, which is built on fragmentation, hierarchical power dynamics, and exclusion, sustainability leadership "identifies and empowers the leader that inherently exists in each person, and fosters strong, healthy, sustainable, and just change through collaborative and creative means" (Burns, Diamond-Vaught, Bauman, 2015, p. 91). This approach to leadership requires a reflective process in which leaders have both self-awareness in relation to 
others and the world, as well as an understanding of how to collectively reflect with others on particular situations. Combining these three elements, their overall view of leadership is one of “...'facilitation' or 'curating', as the core goal is to guide people and organizations to collaboratively create visions and take action for a more sustainable and resilient world" (Burns, Diamond-Vaught, Bauman, 2015, p. 90), a radically different approach than the traditional and normative 'leading over' approach to leadership.

In another take on sustainability leadership, Shriberg (2012) identifies sustainability as a principle that can guide leadership action to solve long-term, complex, and interconnected environmental and related social problems. In this article, Shriberg outlines five skills that are needed for leaders to engage in sustainability leadership to address these issues. These skills are: systems intelligence, or the ability to see systems as an integrated whole; visioning, being able to facilitate a forward-looking and inspiring shared vision of a sustainable future; humility, or the ability of leaders to set aside their own egos in order to meaningfully engage diverse perspectives on solving issues; embracing and capitalizing on change, or effectively being able to facilitate an inclusive process of bringing people and ideas together into new and desired relationships; and an orientation towards enlightened self-interest, which calls on leaders to consider the ethical and long-term consequences of their actions, or inaction, for social and ecological systems. Shriberg (2012) writes that these skills "translate into a leadership model that opens up a collaborative process with more stakeholders that is circular rather than linear and that values multiple forms of input and urgency to address environmental problems" (p. 473). He argues that the shift required of leadership theory to incorporate sustainability is a shift that would contribute to improving leadership of all kinds in the 
increasingly complex world we live in and that all leadership should become an exercise in sustainability in action.

Even though Visser \& Courtice (2011) operate from within the traditional leadership paradigm, their study exploring the common traits, skills, and knowledge of sustainability leaders aligns with other sustainability leadership theories. They found that the traits of the CEOs that had exhibited some form of sustainability leadership included being caring and morally-driven, systemic and holistic, enquiring and open-minded, selfaware and empathetic, and visionary and courageous. The skills they discovered involved being able to manage complexity, communicate a vision, exercise judgement, challenge and innovate, and think long term. Additionally, they found that sustainability leaders needed knowledge of global challenges and dilemmas, interdisciplinary connectedness, change dynamics and options, organizational influences and impacts, and diverse stakeholder views. They also identified that "leadership action is particularly important, because the gap between sustainability aspirations or imperatives and actual performance remains wide" (Visser \& Courtice, 2011, p. 10-11). Although these scholars still see sustainability leadership as something that hierarchical leaders guide their followers to do, their version of sustainability leadership mirrors how relational sustainability leadership theories believe that sustainability leadership should be enacted.

As Evans (2018) and Bendell and Little (2015) describe, sustainability leadership serves the specific purpose of supporting healthy and resilient socio-ecological systems, implying that any specific sustainability leadership competencies or skills must be employed in pursuit of this purpose. As with normative leadership, the skills and competencies for sustainability leadership can be developed in higher education. 
Sustainability leadership development in higher education. Because of the particular purpose and traits of sustainability leadership, sustainability leadership education and development within postsecondary institutions also have particular characteristics. As some scholars consider sustainability and leadership as intrinsically connected and as higher education is often a site of leadership development, developing sustainability leaders can and should take place within higher education with the purpose of “....preparing leaders to be active citizens who address complex and pressing sustainability challenges" (Burns, 2016, p. 1). There has been research into how sustainability leadership and leadership identity develop over time, as well as how it can be cultivated in higher education (Burns, 2016), which this section will review.

In their piece Graduate Leadership Education in a Socio-Ecological Perspective: Working at the Paradigmatic Interface, de Guerre and Taylor (2004) discuss leadership education using what they term a socio-ecological perspective. Using this perspective, they suggest six theoretical principles for designing leadership educational programs intended to support sustainability leadership development, which differ greatly than conventional leadership education. The first principle is that practice is primary and theory illuminates practice, rather than prospective leaders being taught theory without the chance to apply it. A systems perspective and process focus are the second and third principles, reflecting a postindustrial, living systems way of knowing. The fourth is that learning is a process of how to learn that is grounded in experience. The fifth is that collaboration and collaborative leadership are primary, also echoing the principles of postindustrial and sustainability leadership. The final principle is reflexivity, or a way of knowing in which the knower places themselves in the world they seek to know, rather 
than be detached from it. The authors applied these six principles to a graduate level leadership education program to create an "entire program designed on the basis of participants' process of learning that emerges from practical experience generated within the program and relevant conceptual material” (de Guerre \& Taylor, 2004, p. 75), through which they intended to cultivate systemic leadership in their students in order for them to be equipped to help transition the world towards a greater ecological consciousness.

In a similar theoretical exploration of sustainability leadership, Burns, DiamondVaught, and Bauman (2015) describe pedagogical practices that can help to foster the development of sustainability leaders. These practices, which overlap with those described by de Guerre and Taylor (2004), include: observation and self-awareness; reflection; the exploration of ecological and diverse perspectives; and learning experientially and in community. In a later study of graduate level sustainability leadership education, Burns (2016) found empirical evidence to mirror these theoretical pedagogies and principles of sustainability leadership. Her grounded theory study explored the perspectives of 23 graduate students in a course on sustainability leadership in order to understand if and how the students' understanding of sustainability leadership changed and what pedagogies were most influential in their learning through the course. The results showed that the students came to understand sustainability leadership as the facilitation of a shared process, an emergent process, a creative long term process, and way of being, and that they demonstrated changes in their self-understanding. The aspects of the pedagogical design of the course that were found to be influential to the students learning were creating a sense of community, learning from peers, and case-in-point 
experiential learning. In this course, a group project involved all of the students in the course served as the case-in-point learning strategy, in which "what happens in the classroom itself is an opportunity to learn and practice leadership with others" (Burns, 2016, p. 2); in this project, experience, emotions, and reflection played important roles in student learning.

In their article Experiential Learning for Sustainability Leadership in Higher Education, Savage, Tapics, Evarts, Wilson, and Tirone (2015) sought to compare the program design of an undergraduate sustainability leadership certificate with students' perception of their learning within the program. The certificate program studied was in part designed around in Wiek, Withycombe, and Redman's (2011) sustainability competencies, a framework for academic sustainability programs derived from the results of a broad literature review of sustainability competencies. In their study, Savage et al. (2015) analyzed the data from 32 pre/post surveys that included quantitative measures of growth in sustainability competencies, as well as open-ended qualitative questions about the program. The quantitative data revealed that students felt that they had increased their level of confidence and competency in Wiek, Withycombe, and Redman's (2011) sustainability competency areas. The surveys also revealed that the "application-oriented instructional methods resonated strongly with all participants... The supportive, intimate environment provided by the program's small scale was also widely favored by participants" (Savage et al., 2015, p. 696). Additionally, three themed clusters emerged from the open-ended responses: community, future, and personal development. Students expressed the importance of community and it was "often mentioned with respect to sense of place, with an emphasis on feelings of belonging and of having a safe, 
supportive environment” (Savage et al., 2015, p. 698). In addition to a sense of belonging, their learning community also provided an opportunity for students to value and experience the tensions of working with a group of people comprised of different backgrounds and opinions, as well as to practice interpersonal skills in a diverse community. The students' responses also highlighted the significance of the "personal well-being aspect of personal development" (Savage et al., 2015, p. 698), citing activities like self-care as contributing to self-awareness and growth in feeling empowered. The authors stated that students felt that "personal development exercises enhanced their ability to reach the program's target sustainability leadership outcomes, specifically: attaining personal and emotional attributes that would help them behave sustainably, and, acquiring the skills to act sustainably" (Savage et al., 2015, p. 699). This finding highlighted that personal well-being, development, and self-care were important components for students to engage in collaborative sustainability learning and leadership. Finally, the theme of future emerged in the qualitative data, with students articulating that they either felt out of or in control of being able to impact the future, but generally held positive feelings about the future. The findings from Savage et al (2015) and Burns' (2016) studies, which highlight the positive impacts of learning communities and studentcentered experiential learning, align with characteristics that Eich (2008) found of high quality postsecondary leadership programs (Burns, 2016).

In another empirical study, Shriberg and MacDonald (2013) sought to analyze common characteristics of sustainability leadership programs in higher education. They interviewed 20 program directors and analyzed the materials from 50 programs to understand the programs' design and teaching strategies, the principles and assumptions 
underlying these methodologies, and the skills needed for sustainability leadership development. The majority of these were graduate or professional level learning programs and were offered for credit or as a certificate. Despite a wide variation in the type of programs offered, several common features emerged from their analysis: that programs focus on network building, systems thinking, and project-based learning and that "a common linkage between these programs is a focus on experiential learning... based on the potential of experiential learning to ensure that classroom lessons on sustainability can be integrated into practice" (Shriberg \& MacDonald, 2013, n.p.). In addition to these programmatic features, many program directors cited effective communication, systems thinking, self-assessment, and self-analysis as key skills that their programs sought to instill in their students.

Shriberg and MacDonald (2013) also found that many directors noted that "peerto-peer learning" or "diversity of participant perspectives" (p. 12) were the most effective components of their programs, showing that many of these leadership programs employ nontraditional and experiential learning pedagogies. This was seen particularly in programs that employ a cohort format, in which sustainability leadership was strongly viewed as a group process. Shriberg and MacDonald (2013) synthesized their findings into best practices for sustainability leadership program design and implementation, which include: employing experiential learning; integrating disciplines; moving beyond sustainability knowledge to concepts like resilience; building community; moving beyond transformational leadership to include systems and ecological perspectives of leadership; providing change agent training; and defining a specific set of skills for students to acquire. 
In a follow up to their first study, MacDonald and Shriberg (2016) sought to understand how alumni of sustainability leadership programs perceived the outcomes of their learning experiences. Their results, which were derived from 232 responses to a quantitative survey, indicate that while students are generally satisfied with the sustainability knowledge they acquired in their sustainability leadership program, there is a gap in the students' expectation and attainment of sustainability related skills. In their article, MacDonald and Shriberg (2016) relayed that:

Graduates report that they use negotiation, public speaking, facilitation, and coalition building significantly more in the workplace than they were taught in their programs.... Conversely, the skills of self-reflection/assessment, communicating my own story, systems thinking, and being a change agent for sustainability were taught significantly more in their leadership programs than they are used in the workplace.... This may reveal a lack of opportunity to use these skills in the workplace, a lack of attention to the applicability of these skills, or a mismatch between needs in the workplace and academic program delivery. (p. 366-367)

Their findings reveal that while sustainability leadership literature emphasizes systems thinking and dealing with complexity, program design and implementation might benefit students more with a stronger focus on practice-oriented skills.

Summary. Sustainability leadership has been demonstrated to be connected to and apart from normative leadership theories, arising in contrast to the traditional industrial models of leadership that promote ecological, social, and economic unsustainability and in tandem with postindustrial, relational forms of leadership based 
on interconnectedness and working along with others. However, sustainability leadership is differentiated from normative leadership theories and practices in its orientation towards addressing sustainability issues and its purpose of fostering human and nonhuman health, integrity, and socio-ecological systemic resilience. Because of its specific orientation and purpose, sustainability leadership is characterized by certain qualities, such as recognizing the interdependence of people with each other and the nonhuman world, utilizing a systems thinking perspective, embodying a way of being and acting rooted in sustainability values, commitment to facilitating collaborative processes that includes diverse perspectives, and being able to vision a long-term sustainable future, among others. In order to prepare people to engage in this form of leadership, there have been efforts to research and practice sustainability leadership development in higher education. Sustainability leadership development can be supported through educational environments that include communities of learners and peer-to-peer learning, experiential pedagogies, a focus on reflection, process, collaboration, and skill building, teaching systems thinking, and including self-care as part of the curriculum.

\section{Conclusion}

With the growing complexity and interconnectedness of the world and the shift from dominant Western and patriarchal epistemologies towards including perspectives that have traditionally been excluded from academia, the theories and practices of leadership have changed. With the changes from hierarchical and power based leading over industrial leadership approaches to relational and connected leading with postindustrial leadership approaches have come changes to the theories and practices of how to develop leadership in individuals and groups. Within the postindustrial paradigm 
of leadership, leadership development is understood to be based on experience, practice, and reflection.

A subfield of leadership studies is that of student leadership in higher education. Modern student leadership models, situated within the postindustrial leadership paradigm, are based on nonhierarchical collaboration with others and are oriented towards purposeful and values-based social change. Student leadership development, much like postindustrial leadership development, is understood to occur in part through experiential learning, team-based learning, peer education, sociocultural discussions, and contemplative practice, as well as faculty interaction and mentoring. Student leadership development can be augmented by attending to leadership identity development, or how students come to see themselves as able to engage in relational leadership identity, which happens through having leadership experiences and integrating these experiences into one's identity. Student leadership development can also be enhanced by increasing a student's leadership self-efficacy, or the belief in one's ability to enact leadership, as increased leadership self-efficacy can contribute to students taking on more challenging leadership experiences, which will in turn support their growth in their leadership capacities.

Sustainability leadership, another iteration of leadership studies, emerged in the 20th century as well. Sustainability leadership differs from normative leadership in that its purpose is oriented specifically towards addressing the environmental, social, and economic challenges transpiring across the world. Sustainability leadership is characterized by actions taken with others based in sustainability values that support the health and resilience of socio-ecological systems, is based on and operates within an 
interconnected living systems view of the world, and is inclusive, collaborative, and reflective. Sustainability leadership, which anyone can practice, involves facilitating and curating collective action towards increasing the health and resilience of socio-ecological systems through people engaging capacities such as systems thinking, visioning, and humility, which are developed through experience and reflection within community.

Throughout the evolution of leadership theories and practices towards postindustrial and sustainability leadership, encouraging development through leadership education or development programs hinges on "walking the leadership pedagogy talk" (Eich, 2008, p. 186), meaning that if programs intend to develop a certain style of leadership, they must "model and teach the kind of leadership they value" (Eich, 2008, p. 186). Sustainability leadership programs must engage the values of sustainability leadership in their program design and delivery in order to foster sustainability leaders able to address the challenges the world currently faces. The next chapter describes the methods of this study, which sought to explore sustainability leadership development in a co-curricular program within an institution of higher education. 


\section{Chapter III}

\section{Methods}

\section{Overview}

This chapter provides an overview of the research methods used in this study. The purpose of the research and the research questions are presented first. A rationale for using qualitative methodology, specifically grounded theory, for this study is provided next. I then describe and acknowledge my positionality as a researcher. In the research design section I provide a detailed site description, outline the sampling and recruitment procedures, describe the participants, define the data collection, analysis, and verification strategies, and discuss the limitations of this research. Lastly, I discuss the significance of the study.

\section{Purpose and Research Questions}

The central phenomenon studied in this qualitative research project was student sustainability leadership development at Portland State University (PSU). The purpose of this research was to better understand what supports student sustainability leadership development in order for the Student Sustainability Center (SSC) Program Coordinator to be able to support this development through the SSC programs. As has been identified in the literature, sustainability leadership is oriented towards fostering collective change towards a more sustainable world, which necessitates that certain skills and abilities are cultivated in sustainability leaders. Sustainability leadership development is thus a distinct process from other forms of leadership development. This study sought to empirically explore the unique process of sustainability leadership development within a co-curricular program in a higher education setting. The research questions that guided 
this study were: "How are student sustainability leaders developed at PSU?" and "How can staff support or encourage the development of student sustainability leaders?”

To provide further information for the SSC Coordinator, the following subquestions were explored as well: "How do students get involved with sustainability at PSU?" "What are challenges to being involved with sustainability at PSU?" "What are the benefits of participating in sustainability programs?" "What is needed to make a valuable education for students?" and "Does the SSC Leadership Fellows curriculum support sustainability leadership development?" These questions were developed in conversation with the SSC Program Coordinator to provide additional information that would be useful for them.

This study was based on an existing project designed by the SSC Program Coordinator. The SSC Program Coordinator began this project in 2015 in order to understand the ways in which students at PSU became involved with sustainability programming. The SSC Program Coordinator collaborated with another staff member in the Institute for Sustainable Solutions at PSU to design the research questions and obtain IRB approval for the project. These two staff members, along with an undergraduate student employee in the SSC, conducted an initial round of interviews with students and shared their results through conference presentations. However, the project was set aside for some time because the staff did not have the capacity to continue working on it. I, the researcher, started working on the project for my master's thesis in 2018 after discussing the opportunity with the SSC Program Coordinator.

\section{Rationale for Methodology}


Because this study was based on an existing research project and in the needs of the SSC Program Coordinator, it employed a pragmatic methodology (Creswell, 2003). The pragmatic methodology allowed for the study to use the methods that best suited the needs and aims of the already existing research questions and purpose. In order to gain an in-depth and detailed picture of the central phenomenon being explored, the study employed qualitative methods, which allowed for themes to emerge from the data and for the research process to change iteratively throughout the project (Creswell, 2003). The qualitative inquiry was also interpretive, as I, the researcher, made meaning of the data through my personal lens and situated and reflected on myself within the research. I employed holistic methods that sought to understand the complex nature of the central phenomenon through multiple perspectives and multiple modes of information gathering (Creswell, 2003).

In order to understand the development of sustainability leaders at PSU, data on the experiences of student sustainability leaders were collected through interviews and analyzed for themes on how their development occurred and what supported it. This study was based in constructivist epistemology, as it elicited the participants' understanding of their own experience of sustainability at PSU. The specific type of inquiry used to analyze the participants' experience was grounded theory. Grounded theory, a method originally established by Glaser and Strauss (Charmaz, 2014), involves a researcher attempting to derive a general abstract theory of actions, interactions, or processes of people by relating categories or themes found in the data from the experiences of individual participants (Creswell, 2007). The theory generated is thus grounded in the views of participants who have experienced the process or phenomenon 
being studied. This strategy of inquiry allowed the experiences of student leaders to be heard and for themes to emerge directly from the participants, which were then related to each other and developed into a connective theory.

Many aspects of the methods and procedures for this study were predetermined by the original IRB proposal for the project that the SSC Program Coordinator developed in 2015. To meet the needs of the SSC Program Coordinator, the study continued to employ the research design developed in the original project while contributing a theoretical basis to the project and expanding the methodology to ensure that it met the requirements of a master's thesis project. I reviewed the original research questions with the SSC Program Coordinator to ensure they fit with the intent of my study. I completed the IRB ethics training, we amended the IRB proposal for the study to include my work, and IRB approval was obtained for me to conduct this phase of the study.

\section{Researcher Positionality}

It is important for a qualitative researcher to transparently position themselves within their work, as knowledge production is understood to be subjective in constructivist iterations of grounded theory and the epistemology underpinning it (Charmaz, 2014). I, the primary researcher, am a master's degree student at PSU and have been involved with sustainability education and sustainability programming at the PSU campus. I had not worked directly with the SSC prior to beginning my research, although some of the participants were people I knew as a student at PSU.

My interest in sustainability began as an adolescent when I attended Outdoor School in Oregon as a sixth grader. I later volunteered as an Outdoor School Leader as a high schooler and came to love outdoor education. Following this passion, I became 
immersed in farm and garden-based education and sustainable food systems during my undergraduate degree. My path eventually led me back to school where I began the Leadership for Sustainability Education (LSE) program at PSU with an interest in the broad topic of sustainability education.

While in LSE, I became curious about exploring the intersection of critical theory and sustainability. This led me to take classes outside of the program in the Indigenous Nations Studies and Gender, Race, \& Nations departments at PSU. Those academic explorations, coupled with our learning of systems thinking and some of the critical scholarship assigned within LSE, have helped me to gain what I term a "critical sustainability lens." This theoretical lens has been molded by critical theories from across the academy and calls for an analysis of power dynamics, oppression, colonialism, capitalism, and social identity constructs in our academic work. It has become the way in which I view the world. I believe that being able to critically analyze the root systems and structures of power in our society is one of the most important projects we can undertake in any research or knowledge construction. Because I am a person who holds much privilege in my identity, as a woman who is a settler, white, cisgendered, able-bodied, middle-class and more, I felt that it was extremely important to bring this critical lens to my research.

\section{Research Design}

Site description. This study took place in partnership with the Student Sustainability Center (SSC), a co-curricular sustainability program at PSU. PSU is midsized public university located in downtown Portland, Oregon with a large population of commuter and non-traditional students. PSU as an institution is highly engaged with the 
city of Portland, as its mission is to "Let Knowledge Serve the City." PSU is also known for its institutional commitment to sustainability and sustainability programs, which is supported by the sustainable, "green" nature of Portland.

The SSC was founded in 2009 as a collaboration between the Institute for Sustainable Solutions (ISS) and Enrollment Management and Student Affairs (EMSA). Initially the SSC received funding from, participated in shared initiatives, and shared office space with ISS while reporting to EMSA. The SSC was established with the mission of providing sustainability-related leadership and engagement opportunities for students at PSU (Sustainability Leadership Center 2009-10 Report, n.d.). In the 2016-17 academic year, the SSC began reporting to and receiving funding from student fees and the Student Activities and Leadership Programs (SALP) division within Student Affairs. SALP's mission is “to enrich and integrate students' leadership and academic experiences in order to educate students to be ethical, socially just, and civically engaged leaders on campus and in their larger communities" ("About SALP", 2019). As part of the organizational transition, the SSC revised its departmental processes to align with SALP, moved its physical location to Smith Student Union where the SALP offices are, and launched the SSC Leadership Fellows pilot program.

Since the completion of its organizational transition, the SSC has further developed its capacity to combine SALP's mission of student leadership development with a thematic focus on sustainability, providing opportunities for students to engage in experiential learning related to sustainability, to develop their leadership skills within a community of peers, and to contribute to creating positive change in their communities. The SSC offers a multitude of programs for students to engage in that range from short- 
term, structured volunteer activities to more in-depth programs that have specific leadership development outcomes. The programs that the SSC offers include: the Sustainability Volunteer Program, Ecoreps, the Sustainability Leadership Council, and the Leadership Fellows program. Most of these programs encourage students to be involved for at least one academic term, although some short-term volunteer opportunities or one-day events are offered throughout the year. In addition to these programs, the SSC also contributes to organizing on-campus events and series, such as Social Sustainability Month, and partners with off-campus groups, such as the Greater Portland Sustainability Education Network (an initiative of the United Nations University). All of the multi-term programs include a reflection component and working with a group of peers. A sitemap of the SSC programs is provided in Figure 2.

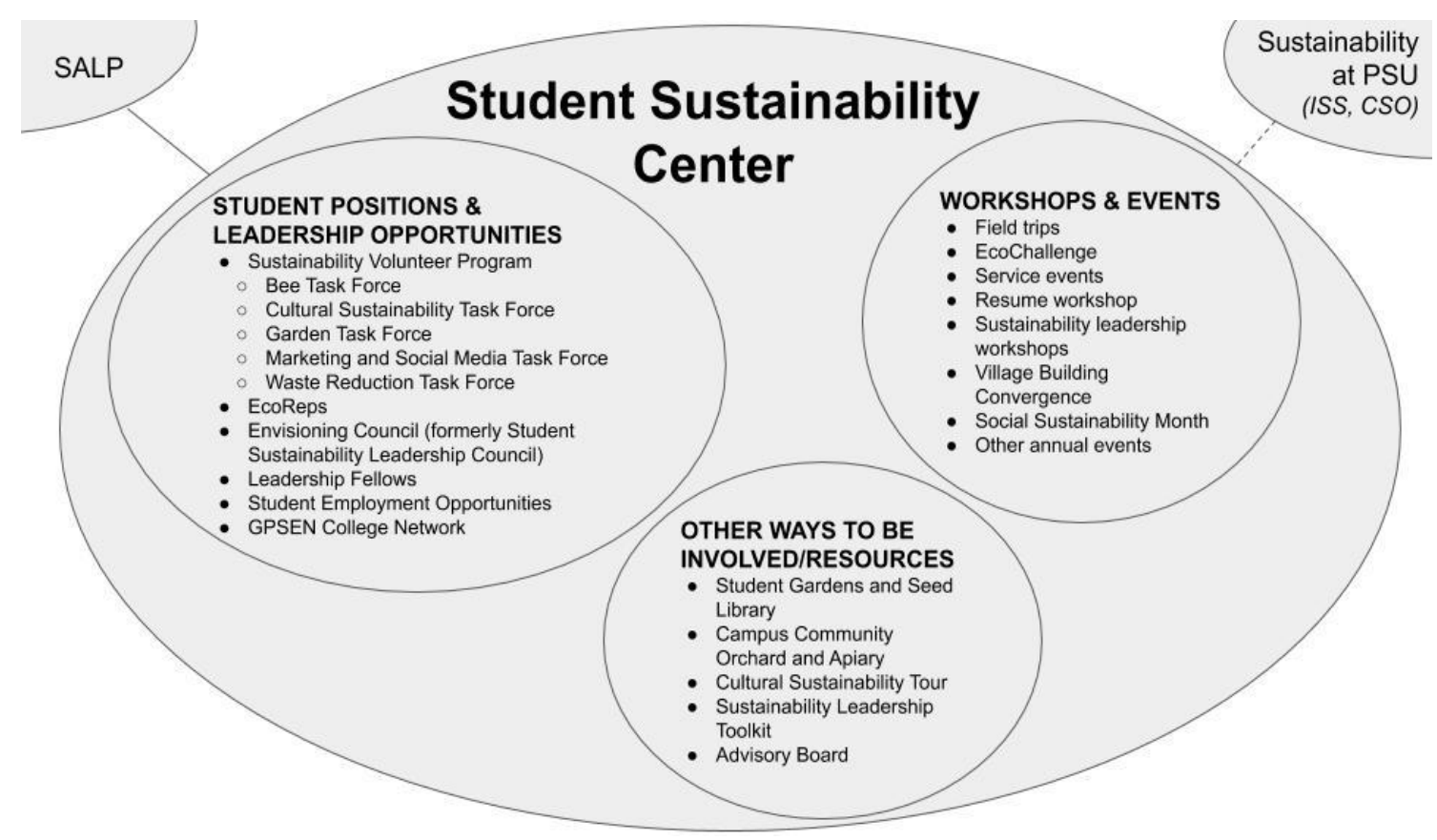

Figure 2. A sitemap of the current Student Sustainability Center programs.

Presently, the SSC is run by one full time professional staff member, the SSC Program Coordinator, with the support of seven student employees. To provide context 
for the program's participants in recent years, as well as the sample from which the participants for this research were selected, the following program demographics are detailed. In the 2016-17 academic year, 89 students participated in SSC programming for at least one term (Student Sustainability Center 2016-17 Impact Report, n.d). During this year, $81 \%$ of students were undergraduates and $19 \%$ were graduate students, $15 \%$ were international students, and $43 \%$ were students of color, with an average student age of 24 . 14 students participated in the Leadership Fellows program and received stipends, and there were six student staff positions. In the 2017-18 academic year, 54 students participated in an SSC program for at least one full term and $60 \%$ of participants were retained from fall to winter term (Student Sustainability Center 2017-18 Impact Report, n.d). Of these students, $50 \%$ were juniors or seniors, $81 \%$ were undergraduates and $19 \%$ were graduate students, $7 \%$ were international students, and $42 \%$ were students of color. The average age of all students was 30 and the average GPA was 3.30. 13 students received financial leadership awards, or stipends, that year for participating in the SSC Leadership Fellows, and there were seven student staff positions. The Leadership Fellows program is described in more detail in the following section.

The "web of opportunities" (Spalding, Williams, \& Wise, 2014) that the SSC provides is intended to allow for student growth and development within the organization. This opportunity for growth is built into the structure of the program, as students who participate in the "entry-level" programming develop the skills needed for more advanced positions. Students that have participated in an SSC volunteer program are also encouraged to apply for a leadership position or student employment within the SSC. For example, a student might initially be involved as an Ecorep, a volunteer who 
helps PSU departments or residence halls implement sustainability projects, which could evolve into participation in a task force or the Leadership Council. From there, the student might apply for a student employment position or a position as a Leadership Fellow, following a self-directed leadership journey through their experiences at PSU (Spalding, Williams, \& Wise, 2014).

The SSC Leadership Fellows. This study evolved to focus primarily on students who had participated in the Student Sustainability Center Leadership Fellows (SSCLF), a program that Student Sustainability Center (SSC) students can participate in. The SSCLF is part of a year-long leadership development experience that Student Activities and Leadership Programs (SALP) implements across all six of its programming areas. Students in the Leadership Fellows participate in yearly cohorts facilitated by two professional staff or one professional staff with assistance from a graduate student throughout the academic year. The SSCLF is comprised of the SSC student coordinators (student staff members), as well as a handful of other students that apply to participate in the program. The Leadership Fellows aims "to create a community of students who come together to focus and reflect on leadership" ("Welcome", n.d.). The program is theoretically based on the Social Change Model of Leadership (SCM) and is focused on developmental learning rather than training or education. Pedagogically, the program employs “...a holistic approach to student learning characterized by increasing complexity and rooted in experience and reflection... [and] is based on Kolb's learning cycle which includes an experiential component" ("Welcome," n.d.). Because of the experiential component, the students who participate are expected to hold a current leadership position at PSU. The cohorts each have three learning outcomes: one based on 
the program-wide theme of the year, which is derived from the theoretical model of the SCM; one learning outcome that is shared across all of the program cohorts; and one that is chosen by each cohort's facilitators. As outlined in the SSCLF course overview, the goals for students who participate in the SALP Leadership Fellows are "to develop leadership skills to better serve their organization; develop understanding, knowledge, and skills that [they] can use in career and community work; and to meet other student organization leaders and share insights" (see Appendix A).

The curriculum for the SSCLF cohort was designed to integrate the topical theme of sustainability into SALP's existing Leadership Fellows program structure. The SSC Program Coordinator develops a sustainability related learning outcome and theme that the students learn about throughout the year. As a part of the SSCLF, students attend sessions with their cohort that include reflection activities, group discussions, panels with sustainability professionals, case studies, and other learner centered activities that draw on the students' knowledge and participation. In addition to the group sessions, the students who do not hold SSC coordinator positions are paired with one of the SSC student coordinators. These students support the programs their SSC coordinators run, taking on extra projects or more responsibilities than other SSC volunteers, such as assisting in setting agendas and facilitating meetings.

The first SSCLF cohort in 2016-17 spanned two out of three academic terms (winter and spring), had 14 students, and focused on "providing in-depth leadership activities, community building, and reflection experiences" around a central theme, the three E's of sustainability (economics, equity, environment), with systems thinking as the guiding framework (Student Sustainability Center 2016-17 Impact Report, n.d., p.2). 20 
students participated in the second year of the program, which ran in 2017-18 and lasted all three terms of the academic year. Student participants voted on a variety of possible themes and choose the theme for 2017-18: Self, Community, and World (H. Spalding, personal communication).

Sampling, recruitment, and participants. This study employed theoretical sampling, in which the researcher chooses participants that can contribute to theory development (Creswell, 2007). Often in theoretical sampling the researcher goes through an initial coding and theorizing process with the data from a chosen group of participants and then returns to the field to gather more data based on the emerging concepts of the theory in order to make comparisons and saturate the categories arising from the data (Creswell, 2007; Strauss \& Corbin, 1998). Given the scope of this project and the criterion set by the project partner, theoretical sampling was not used and a theory was developed from the initial set of participants.

The main data collection method used in this study was one-on-one, semistructured interviews. The students who were interviewed were recommended by the SSC Program Coordinator based on their completion of the SSCLF and on their high levels of involvement with the SSC. The students interviewed for this study were selected from a larger list of potential students to interviews; some students could not or chose not to participate, or did not respond to my inquiries to participate. Not all of the students who were interviewed participated in the SSCLF for a full year, so another criteria in the sample selection was that the SSC coordinator viewed the chosen students as positive role models for sustainability who exemplified the qualities and skills the SSC hopes to cultivate through its programs (H. Spalding, personal communication, April 10, 2018). 
The participants represented an active and diverse set of experiences through the SSC and at PSU. Because this study sought to explore what supports students in their development of sustainability leadership, these participants were chosen because they successfully demonstrated sustainability leadership qualities and skills, as observed by the SSC Program Coordinator. The students were emailed by the researcher to see if they would like to be involved in the study (see Appendix B). Once the students had responded and agreed to participate, the consent form (see Appendix C) and interview questions were sent to the participants to review before the interview.

A total of nine PSU students were interviewed out of a list of sixteen potential interviewees (56\% interviewed). The students represented a wide variety of academic disciplines and stages in their academic careers. Of the students who participated, four were undergraduates and five were graduate students (three doing doctoral degrees and two doing master's degrees). Four students had recently finished or were in the final term of their degrees and five were still completing their degrees. Six out of the nine students were white, two were international students from the Middle East, and one identified as multi-ethnic (black, white, and Latino). The participants' academic programs included business, engineering, education, urban studies, geography, environmental science and management, and women's studies and anthropology. Many of the students held student employment positions within the SSC and were also involved in other capacities at PSU.

Data collection. The data was collected during one-on-one semi-structured interviews between the participants and the researcher. The interviews were held mostly on the PSU campus in private conference rooms or private library rooms. I began the interviews by reviewing the consent form with the participants, asking them if they had 
any questions or concerns about participating, and by obtaining official consent by having them sign the form. The participants were given a copy of the interview questions to look at during the interview. The questions (see Appendix D) had been previously developed by the Student Sustainability Center (SSC) Program Coordinator and the others who were involved in the original iteration of this research; to align with the needs of the SSC Program Coordinator, I kept the questions the same with the exception of the last two questions, which we added to capture the experience of students who had recently graduated. I asked the same questions during each interview, with follow up questions that were meant to clarify what the participants meant or to further explain a point of interest that they had made. I also asked every participant at the end of the interview if they had any other information or points they would like to add. The interviews were recorded on my computer and phone and I took notes on my computer during the interviews. As outlined in the IRB approval and consent form, the interviews were confidential and the students' names have been replaced by pseudonyms.

In addition to the interviews, I observed some of the programming for the Student Sustainability Center Leadership Fellows (SSCLF) to gain a rich understanding of the research site. I also reviewed program documents, such as the SSCLF program curriculum and the SSC and Student Activities and Leadership Programs program websites. While I did not use a specific method of analysis to interpret this information, it informed my understanding of the SSC and SSLF along with the interview data.

Data analysis. All of the interviews were transcribed verbatim using a transcription service called Temi (2019). After being transcribed, I reviewed all of the 
interviews and corrected them for grammatical errors and incorrect words in order to prepare the data for analysis.

Grounded theory analysis involves three stages of coding. Coding is the process of defining what is happening in the data to understand what it means (Charmaz, 2014). The first stage of coding is called open or initial coding, which involves "coding the data for its major categories of information" (Cresswell, 2007, p. 64). Charmaz (2014) states that during the first round of coding "we remain open to exploring whatever theoretical possibilities we can discern in the data... Initial coding should stick closely to the data" (p. 116). This first round of coding is meant to be open ended and the researcher attempts to avoid applying preconceived notions to the data. In the first round of coding I came up with descriptions of what was happening in the data, as well as used the participants' own terms to uncover and describe meaning, known as "in vivo" codes (Charmaz, 2014).

In the second round of coding I drew on Charmaz's (2014) constructivist approach to grounded theory. For this round, I reviewed the first round codes and discerned broader themes from them, choosing or conceptually re-describing codes from the initial round that I found to be important to categorizing the data (Charmaz, 2014). In summary, in the second round of coding I studied the first round of codes to analyze "what [my] codes said and the comparisons [I made] with and between them" (Charmaz, 2014, p. 140). In the third round of coding I organized, connected, and related these themes into three broad categories, forming the final connective theory about the phenomenon studied that arose from the participant's data.

Throughout the analysis process I used memo-writing, a technique in which I wrote down my ideas about the evolving theory as I was coding. Charmaz (2014) writes 
that memoing is an important part of grounded theory research, as it encourages the researcher to reflect on and analyze the codes throughout the research process.

Trustworthiness. In order to ensure trustworthiness of the data, as described by Komives et al. (2005) in a grounded theory study they conducted, I debriefed and reviewed each round of coding with my thesis advisor to receive feedback on my process and the content. Once I had developed the final theory, I reviewed it multiple times with my advisor in order to ensure that the results were clear and in line with the study. I also reviewed the results and final theory with the Student Sustainability Center (SSC) Program Coordinator to ensure that the theory made sense to them within the context of the SSC programming. In addition, I used the information from the SSC program documents and websites to inform my understanding of the programs, which gave context to the experiences of the participants that I was analyzing from the interview data. These three methods of engaging with and making meaning of the phenomenon (the grounded theory data analysis, debriefing the data and theory with my advisor and the SSC program coordinator, and reviewing program documents) allowed me to triangulate the data through multiple methods in order to gain a comprehensive understanding of the phenomenon studied (Carter, Bryant-Lukosius, DiCenso, Blythe, \& Neville, 2014).

Limitations. Because of the scope of this project, I did not use theoretical sampling and chose to base my analysis and results on only one selection of participants. While I felt that my thematic categories were saturated, theoretical sampling can be an important part of grounded theory analysis (Charmaz, 2014), making the lack thereof a limitation of my study. Additionally, the sample size was small because of the scope of my project and because I did not employ theoretical sampling. Because of the small 
sample size this theory is not generalizable, although the aim of grounded theory is not to produce a generalizable or transferable theory, it is to gain an understanding of a phenomenon through "thick" description and participant voices (Komives et al., 2005).

Another limitation of the study was that there was no way to verify whether or not the students chosen to participate in the study were leaders besides the word of the Student Sustainability Center (SSC) Program Coordinator. No other measures, such as self-assessments or observation of the students' leadership abilities were included in this study, meaning that there was no way to verify that these students demonstrated leadership abilities in practice. An additional limitation was that only students who had been identified as leaders were included in this study. Students who did not continue to participate in the SSC or become leaders would add an important contribution to understanding the barriers to participating in sustainability programming at PSU.

\section{Significance}

Gaining a better understanding of student sustainability leadership experiences and student sustainability leadership development can help the Student Sustainability Center (SSC) Program Coordinator and other Student Activities and Leadership Programs (SALP) staff create programs that encourage students to be successful in their sustainability leadership development journey. The results of this study are specifically useful for the SSC Program Coordinator, who can use the theory generated to inform the SSC's focus and design, as well as the SSC Leadership Fellows curriculum. This is the first time any research has been done on the broader Leadership Fellows program within SALP, thus it could also help to inform SALP's practices for the whole Leadership Fellows program. Additionally, the larger Leadership Fellows program has a rotating 
learning outcome each year; every three years the SSC Coordinator will design a sustainability theme for all the cohorts in the program; this study could help inform the design of this theme. Given the growing necessity of and interest in sustainability leadership, the results of this study can help inform the SSC, SALP, and Portland State University's actions towards and commitment to creating a more sustainable world.

Lastly, there has not been much research on bridging sustainability and student affairs. The field of sustainability within student affairs is growing; the SSC Program Coordinator has been involved with a project to design sustainability related standards for the Council for the Advancement of Standards in Higher Education, which were recently approved. While not meant to be generalizable, this research could be used as a case study to educate other co-curricular sustainability leadership programs about the SSC.

\section{Conclusion}

The methods detailed in this chapter were used to explore the phenomenon of student sustainability leadership development in a co-curricular program at PSU. The qualitative methods used were meant to elicit the students' experiences to gain a rich understanding of the phenomenon. The following chapter describes the results found in the research. 


\section{Chapter IV}

\section{Results}

This chapter reviews the results and themes from the grounded theory analysis in the context of addressing the study's research questions. First, the themes related to the main research question, "How are student sustainability leaders developed at PSU?" are described. The second section describes the results for the remaining research questions. These questions included: "How can staff support or encourage the development of student sustainability leaders?" "How do students get involved with sustainability at PSU?" "What are challenges to being involved with sustainability at PSU?" "What are the benefits of participating in sustainability programs?" and "What is needed to make a valuable education for students?" The first section addresses the theoretical aspect of student sustainability leadership development, while the second section describes themes related to Student Sustainability Center programming.

\section{Theoretical - How are Student Sustainability Leaders Developed at PSU?}

This study sought to explore the phenomenon of how student sustainability leaders are developed in higher education, specifically at Portland State University (PSU), through the question: "How are student sustainability leaders developed at PSU?" Through the grounded theory data analysis, three themes emerged related to how sustainability leadership was developed in students: community, holistic sustainability, and holistic self, which will each be described in detail in this section. Although I have distilled the student responses into distinct themes, the threads found within the themes are all inherently connected. The findings are summarized in Table 1 (on page 83). 
Table 1

Themes that Support Student Sustainability Leadership Development

\begin{tabular}{|c|c|c|}
\hline COMMUNITY* & HOLISTIC SUSTAINABILITY & HOLISTIC SELF \\
\hline $\begin{array}{l}\text { Participating in and Being a Part } \\
\text { of an Interdisciplinary and Diverse } \\
\text { Community with Shared Values } \\
\text { and Interests }\end{array}$ & $\begin{array}{l}\text { Developing and Learning } \\
\text { About/Applying a Holistic } \\
\text { Understanding of Sustainability }\end{array}$ & Developing a Holistic Self \\
\hline Learning in/from Community & $\begin{array}{l}\text { Learning Social Sustainability* and } \\
\text { Broadening Sustainability } \\
\text { Knowledge and Understanding }\end{array}$ & $\begin{array}{l}\text { Practicing Self-Care in } \\
\text { Community }\end{array}$ \\
\hline Networking & $\begin{array}{l}\text { Cultivating and Applying a } \\
\text { "Sustainability Lens" }\end{array}$ & $\begin{array}{l}\text { Engaging in Whole Person } \\
\text { Growth }\end{array}$ \\
\hline \multirow[t]{2}{*}{ A Sense of Support or Belonging } & $\begin{array}{l}\text { Developing Cognitive Abilities that } \\
\text { Support Holistic Sustainability } \\
\text { Understanding }\end{array}$ & $\begin{array}{l}\text { Having the Chance to } \\
\text { Develop and Practice } \\
\text { Relational Skills }\end{array}$ \\
\hline & $\begin{array}{l}\text { Having the Opportunity to Act } \\
\text { On/Apply Sustainability } \\
\text { Knowledge }\end{array}$ & \\
\hline
\end{tabular}

Note. Community and learning about social sustainability $(*)$ came up across all of the interviews as the most salient and consistent themes throughout the data.

Community. One of the major themes that arose across students' responses to all of the interview questions was that of community. Participating in and being a part of an interdisciplinary and diverse community with shared values and interests was mentioned by all of the students in some way as being important to their experience and sustainability leadership development. The theme of community came up in many ways, as students described that community could be a source of learning about holistic sustainability, an opportunity to create a sustainability network, and source of support or belonging that allowed them to grow as leaders. While many of the students highlighted the importance of the co-curricular community in the Student Sustainability Center 
(SSC), some students also spoke about the community gained from their academic programs, other co-curricular programs, or student employment positions.

Learning. Participating in a diverse and interdisciplinary community, especially in the co-curricular setting of the SSC, was important to student learning about sustainability and sustainability leadership. When asked about what skills were most important to their success, one student, Sam, responded: "I think the most important thing for my success was having a community, especially a community of both diverse and like-minded individuals, so people that I shared values with but could learn from was really important." Another student, Harper, described a similar phenomenon:

And the Sustainability Fellows, I learned so much from that last year. Because there's people from all different disciplines and you learn so many things that maybe I wouldn't learn about in classes. Even business majors and stuff. I feel like you can connect all different kinds of fields to what you're learning too, which is really cool.

As demonstrated by these students, having the opportunity to learn about sustainability from peers across disciplines and life experiences was an important part of the students' experiences and their sustainability leadership development. Learning in their cocurricular community provided students the opportunity to gain an interdisciplinary and holistic understanding of sustainability, which will be described in more detail later in this chapter, as well as to learn relationally with other people that held shared values around sustainability, which is an important part of learning about relational and sustainability leadership models. 
Network[ing]. Another important aspect of the importance of community to student sustainability leadership development (SSLD) was the network of people created from the community and the professional opportunity for networking. One student, Sam, described: "So I've really gained the skill of networking, but I've also gained a bigger network not only on campus but definitely in sustainability communities. And that's also helped me to find... what I'm really passionate about." The community focus of the SSC often provided students a chance to connect with people on and off campus, creating opportunities for them to learn about and do sustainability work. Dana, another student, expressed a similar sentiment:

...It's really helped me network with great people, not only on-campus but offcampus. And through this I have a dream to do eventually, which is working with the United Nations one day. I learned through [the SSC Coordinator] and the people I got to know about GPSEN [Greater Portland Sustainability Education Network]... I got involved in that and I'm working with an international group and it's very hard to find time to do that. But again, this helps me to really get to know great people with the same interest and get motivated with each other and learn from each other.

Getting involved with a sustainability network allowed students the chance to engage with, apply, and practice sustainability with others. Having the chance to do sustainability also created opportunities for them to discover their passions, develop their interests, and have the motivation to practice sustainability leadership. Practice and experience are key pedagogies for fostering leadership development, thus students having a network within 
which they found opportunities to do sustainability work was an important part of their SSLD.

Support and belonging. Students also spoke about community as an important source of support and belonging in their development as sustainability leaders. The undergraduates that were interviewed all identified seeking a community as a reason for them to get involved with co-curricular programming at PSU, while the graduate students identified other reasons to get involved, such as valuing engagement or wanting to make change on campus. Some students described the community they found as a way to cultivate their sense of place or sense of belonging at PSU, such as Taylor, who articulated this as their reason for getting involved with the Student Sustainability Center:

I knew that I needed to find a sense of place here because I definitely am not a traditional student so I couldn't fit in with the students here. I felt really out of place, so I just knew I had to find something to anchor me here. Taylor spoke about retention in their interview; this quote shows how they got involved with the SSC in order to find a sense of place, which they knew would support their ability to be successful in the development they experienced at PSU.

Students also articulated the general feeling of support that being a part of a community provided to them. This was expressed in many ways, as Kaden said: And then there are places on campus that I consider safe spaces where I can talk to people and just share experiences and realize that you can't go through this whole process on your own. And when I say this whole process, I mean getting a graduate degree and that we exist in an institution that doesn't necessarily 
understand the realities of a lot of its students. And so we have to be able to talk to each other.

As this student describes, having people to share their experience with on campus was integral to being able to get through their degree. Sage, another student, also spoke to the resilience their sustainability-related academic community provided them:

I think I've found a lot of strength in the community from my peers in [my academic program]. It's always been the place to process what was happening... I think finding strength in my community and being open to processing things out with people and share where I was at was the best strategy that I had and still have.

This quote again highlights the importance of having people to share the university experience with, whether it's from academic or co-curricular community.

Another student, Badr, specifically described how the SSC community positively impacted them:

So when I got this message, support, care, I said OK just stick with this, with this group and you will make it... Without that, without [the SSC staff] who told me 'We can work together, don't worry, we work together on English' I would say OK I cannot make it and I leave that being weak and afraid of talking to people for years. But they gave me peace, support, and they pulled me to this sustainability, so I would say this is the care, this is the love, this is the support from SSC. I'm really thankful for these people.

As all of these students described, being a part of the community, often the SSC, provided integral support for them to make it through their college experience 
successfully, as well as through their learning of sustainability and leadership concepts. Being a part of a community provided them the confidence and motivation to engage in leadership development, as well as a space to attend to their whole selves by processing and reflecting on their experiences, an important practice in leadership development. Sustainability leadership development occurs through cultivating people holistically; having a sustainability-oriented community in which students were able to tend to their affective, personal lives, as well as develop cognitively, was important for the students' sustainability leadership development.

Holistic sustainability. Another major theme that emerged from the data was that student sustainability leadership development (SSLD) was supported by students developing and learning about and applying a holistic understanding of sustainability. This theme was broken down into four sub-processes: learning about social sustainability and broadening sustainability knowledge and understanding; cultivating and applying a sustainability lens; developing cognitive abilities that support holistic sustainability understanding; and having the opportunity to act on or apply their sustainability knowledge. This holistic understanding was gained through co-curricular experiences, many of them through the Student Sustainability Center (SSC), and a combination of academic and co-curricular experiences for those students whose academics included sustainability.

\section{Social sustainability and broadening sustainability knowledge. Besides}

community, one of the other major themes that came up across the student interviews was that of "social sustainability." Social sustainability, one of the three pillars of sustainability (National Research Council, 2011), is in and of itself a complex concept 
that students spoke about in many ways. To simplify my analysis, I categorized different terms or interpretations of social sustainability that students described, such as environmental justice, social justice, diversity and inclusion (when discussed as related to sustainability), and cultural sustainability, into the umbrella term of social sustainability. While all of these concepts might not traditionally be considered social sustainability within the context of the three pillars of sustainability, I put them together because they indicated an awareness of the social component of sustainability as well as critical thinking about social issues.

Social sustainability was mentioned by many students as one of the most important sustainability concepts they learned. This was demonstrated by two students' responses to the interview question asking them what the most important sustainability concepts they learned were: "I would say the importance of cultural and social sustainability and different environmental justice issues are what have stood out to me the most. And really I've learned that mostly through the SSC..." (Sam); "I think definitely the social component of sustainability and also the intersectionality of sustainability and that it's about economics and power and environment and people, and I didn't really get that when I first got here" (Noel). These quotes highlight that learning about social sustainability was an important part of the students' college experiences.

Learning about social sustainability in turn led to a broadened understanding of the concept of sustainability for many students. Dana described that:

My knowledge got broader about sustainability, being involved in these resources on campus. Like studying, for example, the effect of climate change on this earth, it is kind of limited scope. But being outside that and meeting other leaders from 
really different majors, from business major, from geography departments. I was thinking sustainability is just about the environment and pollution and you know, but it's, no, it's much, much bigger than this.

Being able to connect with people from across the university and learn about different aspects of sustainability through co-curricular programming allowed this student to broaden their understanding of sustainability. Another student, Badr, described a similar phenomenon:

My understanding of sustainability before I came here was about just clean water, air pollution, these are the main points about the sustainability in my country. But when I came here I found, as an international student, I found that I had culture shock. It was kind of like connecting this sustainability with social science and engineering science. So I found this sustainability at this time, 'Ok let me know more about sustainability, how can I get over my culture shock.' So at that time I found that SSC was a good center, good resource for me to learn about American culture, to learn about other task force for the sustainability that I didn't know before and I found that it's really interesting and honestly SSC, because of that SSC became my big reason to channel myself, my leadership, not focusing just on engineering, focusing on social justice, diversity, culture.

This student also described co-curricular programming, specifically the SSC, as a place where they were able to broaden their understanding of sustainability, particularly by adding an understanding of social sustainability to their previous environmental understanding of what sustainability was. This was a common theme for students whose 
academics did not include learning about sustainability and particularly for the students who were in degrees such as environmental management or engineering.

Learning about the social aspect and broadening their definition of sustainability led students to develop a more holistic understanding of sustainability. This was exemplified by students who recognized the three pillars of sustainability (National Research Council, 2011), such as Kaden who, in response to the same question about the most important sustainability concept they learned, said: "That in order to have true sustainability it has to be at the intersection of environmental sustainability, economic sustainability and social sustainability." Another student, Harper, expressed a similar sentiment by describing the multifaceted nature of sustainability at PSU:

But also through the different programs in the SSC too, I feel like that is telling to the concept of sustainability that there's a garden club and the cultural sustainability task force and then social media, there's so many different ways to communicate sustainability.

Both of these students, as well as quotes from previous students, demonstrate how their understanding of sustainability broadened to include topics related to social sustainability, which helped them develop a holistic understanding of the interconnectedness of sustainability concepts. This learning occurred through cocurricular programming, and the SSC in particular, for many students. This is an integral part of their student sustainability leadership development, as students need to understand the complexity of sustainability in order to be sustainability leaders. Developing a holistic understanding of sustainability concepts allows students to engage in and practice sustainability leadership, as sustainability leadership requires a holistic way of thinking to 
address complex and multifaceted sustainability challenges. This finding is also highly related to the importance of community, as learning about sustainability in an interdisciplinary community often helped students develop this holistic understanding of sustainability.

Cultivating and applying a sustainability lens. Along with their learning of holistic sustainability, students were able to see the world through a "sustainability lens." This theme was derived from an in vivo code from Noel, who said:

I think one sustainability skill that I gained was how to bring a sustainability lens to anything, and to whatever I do... That's one really tangible sustainability skill that I've gained is how to bring that with me, whether what I'm doing is explicitly sustainability work or not, like how to bring that lens to it. So I gained that from the SSC.

The sustainability lens, or being able to take sustainability concepts to other settings or situations, was described by Harper when asked if their curricular and co-curricular experiences both covered sustainability:

Yeah, pretty much all of them have. Well I also, so I've been involved in the SSC and then also I was a Resident Assistant. And I am a Peer Mentor right now too. And so those two things, they didn't initially involve sustainability, but I feel like I have tried to integrate it in some capacity.

Another student, Val, described their plan to take an environmental sustainability perspective to their upcoming summer job: "I'm really excited to work at the camp in order to bring more environmentally friendly practices into what we do because that hasn't really been a focus before." Having and being able to apply a sustainability lens, as 
these students demonstrate, is an important part of sustainability leadership because it enables students to take sustainability leadership into the rest of their lives and work, to practice the sustainability leadership skills they acquire, and to enact the type of leadership that involves seeing all people and opportunities as related to creating a more sustainable world. Since anyone can practice sustainability leadership, cultivating a sustainability lens allowed students them to become dispersed sustainability leaders and enabled them to enact change in any situation they found themselves in.

Developing cognitive abilities. Students need the cognitive abilities that support their understanding of holistic sustainability concepts and the ability to apply these concepts to other situations. Two of these cognitive abilities that students identified or described were critical thinking and systems thinking. Some instances of students describing cognitive abilities that support a holistic understanding of sustainability were mentioned in the context of academics, especially for those students who learned about sustainability in their academic programs, as well as in co-curricular programming through the SSC.

Critical thinking plays a role in being able to holistically understand sustainability. Taylor, when asked about the most important skill for their success, immediately said critical thinking. Kaden demonstrated critical thinking by describing their critical perspective of sustainability at PSU:

And I've been able to share a lot of my sustainability experience with other people on campus. So that's been really good because I've been able to include a lot of people in the conversation who felt isolated from sustainability and mainstream sustainability on campus, which is not super inclusive. Certain 
people, certain sustainability people on campus get it, the need to be more inclusive, and some don't.

Being able to critique sustainability efforts at PSU, as this student does, demonstrates the ability to engage in critical thinking. Students often demonstrated critical thinking in relation to issues of social sustainability, highlighting importance of teaching social sustainability as a means to encourage critical thinking.

Another cognitive skill or ability that students mentioned was systems thinking. Some students, such as Sage and Sam, named systems thinking explicitly as an important sustainability skill or concept they gained through their education. Other students demonstrated systems thinking abilities through their descriptions of sustainability work in their academics or co-curricular programming, such as Harper, when describing an important sustainability concept they learned:

How humans and the environment are very connected. That's why I switched to geography because I kind of felt like, and it's not like this, but the classes I was taking for environmental science just felt very like environment focused and humans play a huge role in the environment and sustainability. Yeah, I guess that's a huge concept to me. Like right now I'm doing my thesis on the hydrosocial cycle. So like the hydrologic cycle, you know... Society plays a huge role in the patterns of the hydrologic cycle.

Even understanding the concept of the three pillars of sustainability or a holistic understanding of sustainability concepts demonstrates systems thinking, as sustainability knowledge requires the understanding of complexity and interconnectedness typical to systems thinking. Common ways that students described their systems thinking abilities 
were "being able to see the whole picture" or "understanding how everything is interconnected." Variations of this concept were said by many students, such as Val, when describing the sustainability skills they gained: "The ability to think about the whole big picture and understanding how everything is interconnected and one thing affects another thing just really understanding why it matters and where one thing comes from and where it goes." This understanding of complex interconnection and seeing the whole picture, which is required to understand sustainability and relationality, is important to be able to practice holistic sustainability leadership. Being able to engage in systems thinking and critical thinking is an important aspect of sustainability leadership, thus students developing and demonstrating these cognitive skills is an important contributor to their student sustainability leadership development.

Having the opportunity to act on or apply their sustainability knowledge. The

final process that supported students in their learning of holistic sustainability moved beyond the conceptual and into application, when students were provided the opportunity to practice the sustainability leadership concepts they were learning. Many students described projects, in both academic and co-curricular settings, where they were able to use and apply their holistic sustainability lens or understanding. Sam, when describing the overall student sustainability experience at PSU, said:

I think the SSC and the clubs at PSU also work to diversify the types of sustainability topics people can talk about as well as being involved in and really create a co-learning, praxis kind of environment. And that's what I really valued about the sustainability experience at PSU. It gave me the platform and tools to practice what I was learning in environmental studies and enhance it rather than 
just focusing on theory or lab reports that were removed from the community focus.

In particular, this student was describing how co-curricular programs allowed them to practice the concepts they were learning in academics to the community context. Noel communicated a similar sentiment:

...when I have the chance to choose a project or to do a paper about something, I usually made the conscious decision to like give it a sustainability focus and I think that that is just like an innate interest that I have in it and PSU has allowed me an environment in which I really practice that and hone that.

These students both highlight how important it was to their experience and development to have a chance to put their understanding of and interest in sustainability to practice, as leadership is understood to be philosophy in action and an effective way to develop sustainability leadership is through practical application and experience.

Another aspect of the process of applying sustainability was the focus on action.

One student, Dana, spoke about action as related to their goals for the future:

So I believe I put my knowledge altogether in my work and I'm hoping in the near future also to continue in that and hopefully at one time I will have an action, is not only a research thing but maybe being part of some program or... Yeah, that's the goal actually. That's one of my goals.

Dana here describes how it is important to them to at some point in the future apply their research on a sustainability related topic and have an "action in it," demonstrating the desire to act on their academic sustainability knowledge. An important aspect of student sustainability leadership development then is not only providing students the opportunity 
to learn about and practice sustainability, it is instilling in students the desire to take action. This creates a holistic understanding and ethic of sustainability, as it takes the idea of sustainability from conceptual to applied in the students' academics, work, and lives. This finding is also highly related to the theme of community, as students may come across a chance to apply their sustainability learning through opportunities found from their sustainability networks.

While many students demonstrated an understanding of holistic sustainability, there was some incongruence in the way that students spoke about applying these concepts. When describing sustainability efforts they had engaged in, whether in their personal lives, applied academic projects, or work settings, multiple students discussed recycling efforts or making less waste by using personal coffee mugs, among other examples. While waste management is an important part of environmental sustainability and highlights an awareness of the mindsets and systems that cause unsustainability, less students provided examples of applied actions or practices that reflected the holistic nature of sustainability. This included a lack of examples of taking social sustainability actions, perhaps suggesting that students have a cognitive awareness of social sustainability but might not have the ability to apply this holistic understanding of sustainability or are not given the opportunity to apply it.

Holistic self. The third major theme found to support student sustainability leadership development (SSLD) was developing a holistic self. Three sub-themes related to this theme emerged from the data: practicing self-care in community; participating in programs that promote whole person growth; and having the chance to develop and practice relational skills. This theme is highly interrelated with the theme of community, 
as many examples of this development were expressed by students in relationship to community.

Practicing self-care in community. All of the students spoke about self-care in some way in their interviews. Some students described self-care explicitly, such as Sage who spoke about self-care as an important sustainability concept they learned through their sustainability-related academic program:

I'm not a very warm and fuzzy person and a lot of the "woo" in our [academic] program was really difficult for me, and I think learning to let some of that in and have some more self-reflective or self-care practices was also a skill that I learned...

While Sage came to learn about the importance of self-care through their academics and mentioned it explicitly, many other students also spoke about ways in which they practiced taking care of themselves. These strategies included getting enough sleep, exercising, taking time for breaks and for oneself, spending time with friends, learning how to set boundaries, and many more, demonstrating how students are reflective enough to be aware of their needs and the diverse ways that they practice self-care. While multiple students described learning about self-care through Student Sustainability Center (SSC) programming, some students said that they learned about it through their academics or even through experiences in their personal lives, like reading a book or hearing a podcast that had an influence on them.

As has been described earlier, community was an important contributor to the students' sustainability leadership development. Community and self-care were described together by many students, highlighting the interconnection of these themes and the 
importance of participating in a community that practices and values self-care for SSLD. Noel describes this overarching interrelated theme when describing the sustainability skills they gained:

As for other sustainability skills, sustaining myself and learning how to do that. I think I learned that a lot from my Women's Studies classes, from my peers in those classes and from my peers at the SSC. I also think I learned a lot about sustaining communities of people, because self-care is good, but at the end of the day sometimes you need people and it's not a bad thing to need other people or to rely on other people. I really, really learned about through Leadership Fellows. So that was a very tangible thing that I learned is that it's okay to ask for help and to lean on your community and to ask for help from your community to sustain you. But then also like, how do you give that back to the community?

This student learned the importance of relying on community in order to sustain themselves, as well as to be able to give back. Sam described a similar sentiment:

When I started the self-care internship, which is through the Student Sustainability Leadership Council, I was focusing more on studying self-care than actually practicing it, so at the time it was a lot more personal things that I think were keeping me from fully taking care of myself.... But I think what's really helped me... is just being involved with communities of people who also care about taking care of themselves... I've been really lucky as an Indigenous Nation Studies minor and involved with the SSC to have structured places for reflection and discussion around personal topics and political topics that sometimes people avoid talking about. 
These two students aptly describe that practicing self-care within community is highly important to their college experience and to their understanding of and application of sustainability leadership. Having a community of peers to lean on for support, to engage in personal growth with and to be in relationship with provides students the opportunity to practice the relationality of sustainability leadership. It also provides students a place to learn how to take care of themselves in order to continue doing the work they are passionate about, as well as to practice the ethic of care inherent to sustainability work and relational leadership. Students learned that in order to do the work of sustainability leadership they have to extend care towards themselves as well others, as sustainability is built on the idea that everything is connected. By sustaining themselves, they contribute to sustaining others and are also able to continue engaging in sustainability leadership. This category and theme often came up in relation to co-curricular programming, mainly the SSC, as many students gained a sense of community from the SSC.

Whole person growth. Another theme that supported student sustainability leadership development was the opportunity to develop as a whole person through university programming. Sage, when describing what they thought college success was, said: "People getting a wide and varied experience and are different at the end, who have been transformed by their experience. I'd say that's successful." This demonstrates an understanding of the holistic ways in which students can grow through their college experience.

Many students expressed a similar appreciation for holistic involvement and growth. Dana also described this when asked about college success: 
So to me it's not only getting the degree. I believe getting the degree, yes, it's one of the goals. But how you live, how I lived that period, how I got engaged on campus, how I got to know people that I'm really honored and lucky to meet during these years. That's important because that can take you wherever next. Okay. I got the degree but then what, you know. So sitting and studying, studying, studying, studying and not knowing anything, not knowing about the resources available, that's not correct. I don't think this is correct. I think networking is important. Connecting to people, finding resources. And again, like the sustainability program was providing such great opportunity on campus.

Many of these students, while having been selected for their leadership and involvement on campus, demonstrate how important being engaged beyond academics is to their experience and holistic development.

Students also demonstrated that they enjoy and value holistic development. Badr, when asked about how they maintained balance during their college experience, said: "And I told you I took the path of volunteering and leadership as a fun activity for me. If it was not fun, I would not be able to do it." Harper also described this sentiment when talking about college success:

I think that it means that you're getting everything that you need to out of your education. I mean, we pay for education, we choose to be here. So I feel like if you're showing up and you're taking what you need to from classes and stuff, to me that means success. But also not just going to classes, getting involved in other things as well. And connecting with people on campus is a very big thing. I always thought that it meant like getting good grades, but I don't think that 
necessarily means that you're successful, I would just say getting involved and finding your community.

Being involved in a community or programming outside of academics that encouraged growth across a spectrum of areas was important for SSLD, as personal growth is needed to engage in relational and sustainability leadership. Students, often through the SSC, had the opportunity to learn about themselves in order to be able to work with others and engage in the change-making practices of sustainability leadership. This sub-theme again highlights the relationship between themes, as much of the student's whole person growth occurred within the context of community.

Relational skills. The final sub-theme of holistic self that contributed to SSLD was having the chance to develop and practice relational skills. These were gained through co-curricular experiences, often through the SSC, although some students spoke about gaining these skills in their other co-curricular experiences or their academics. Students described a variety of different skills that they had gained, many of which were centered around working with, connecting to, and being in relationship with others. Some of the skills, both in general and in relation to sustainability, mentioned were: listening, communication, collaboration, networking, asking for help, advocating for themselves, sharing, facilitation, and engaging with diverse perspectives.

Leadership was a skill that some students mentioned, however only three students self-identified as leaders or as using leadership skills. Two of those students described their conceptualizations of leadership, such as Badr who, when speaking about the SSC, said: "Leadership is about care, it's about support. And with that care and support you can make a good path for other people. And this happened with me.” This quote 
highlights their understanding of a relational view of leadership, which they saw as a process of supporting and working with others. Dana also demonstrated this relational view of leadership:

Leadership for me is not to be the only leader. It's not that. It's how, it's a person who can sit with people and get involved and can lead conversation for example, or organize an event for example. But it's not a one person work. I don't believe. It's not necessarily always a one person work.... It's not a one person works for sure.... And as I said, it's a learning process. Being a leader is not the strategy like you are, I am the best, but how to deal with that position.

While only a few students spoke about leadership directly, most students discussed relational leadership skills. Having the chance to develop these skills and practice them in community was an important part of the students' sustainability leadership development, as relational and sustainability leadership are understood to be learned through experience.

Summary. In summary, the data showed that student sustainability leadership development in these PSU students was supported by: 1) Participating in and being a part of an interdisciplinary and diverse community with shared values and interests that provides students a place to learn, network, and find a sense belonging and support; 2) Developing and learning about and applying a holistic understanding of sustainability by learning social sustainability, broadening their sustainability knowledge and understanding, by cultivating and applying a sustainability lens, by developing cognitive abilities that support holistic sustainability understanding, and by having the opportunity to act on/apply their sustainability knowledge; 3) Developing a holistic self through being 
able to practice self-care in community, participating in programs that promote whole person growth, and having the chance to develop and practice relational skills. While all of these themes were prevalent in the data, the most salient aspects that came up consistently across all of the interviews were the importance of community and the importance of learning about social sustainability.

\section{Programmatic Results}

This section describes findings related to the programmatic aspects of student sustainability leadership development and addresses the following research questions: "How can staff support or encourage the development of student sustainability leaders?" "How do students get involved with sustainability at PSU?" "What are challenges to being involved with sustainability at PSU?" "What are the benefits of participating in sustainability programs?" and "What is needed to make a valuable education for students?"

\section{How can staff support or encourage the development of student}

sustainability leaders? As described in the previous section, student sustainability leadership development (SSLD) is supported by three themes: community, holistic sustainability, and holistic self. Thus, staff at PSU, such as the SSC Program Coordinator, can support the development of student sustainability leaders by implementing the theoretical findings from those themes, illustrated in Table 2 (on page 105). 
Table 2

Applying Theoretical Student Sustainability Leadership Themes to Program Design

\begin{tabular}{|c|c|c|c|}
\hline Theme & Program Considerations & Outcome & $\begin{array}{c}\text { How staff can support } \\
\text { SSLD }\end{array}$ \\
\hline Community & $\begin{array}{ll}\text { - } & \text { Community oriented } \\
\text { - } & \text { Interdisciplinary and } \\
\text { diverse } \\
\text { - } \\
\text { Shared values and } \\
\text { interests }\end{array}$ & $\begin{array}{l}\text { Interdisciplinary, peer- } \\
\text { to-peer learning } \\
\text { - Creates networks } \\
\text { - Creates a sense of } \\
\text { support and belonging } \\
\text { for students }\end{array}$ & $\begin{array}{l}\text { Create an environment in } \\
\text { which students have people } \\
\text { to learn from, engage with } \\
\text { different perspectives, and } \\
\text { have a safe space to practice } \\
\text { leadership. }\end{array}$ \\
\hline $\begin{array}{l}\text { Holistic } \\
\text { Sustainability }\end{array}$ & $\begin{array}{l}\text { - Social sustainability } \\
\text { content } \\
\text { - } \quad \begin{array}{l}\text { Develop cognitive } \\
\text { abilities }\end{array} \\
\text { - } \quad \text { Experiential learning }\end{array}$ & $\begin{array}{ll}\text { - } & \text { Broadens } \\
\text { sustainability } \\
\text { knowledge } \\
\text { - } & \text { Fosters critical and } \\
\text { systems thinking } \\
\text { - Applying \& practicing } \\
\text { concepts }\end{array}$ & $\begin{array}{l}\text { Design programs in which } \\
\text { students gain a holistic } \\
\text { understanding of } \\
\text { sustainability and } \\
\text { sustainability leadership } \\
\text { concepts that they are able } \\
\text { to practice applying and that } \\
\text { they can take with them to } \\
\text { other situations. }\end{array}$ \\
\hline Holistic Self & $\begin{array}{l}\text { Community that } \\
\text { values self-care } \\
\text { Attends to body, } \\
\text { mind, spirit } \\
\text { - } \begin{array}{l}\text { Relational skills } \\
\text { development }\end{array}\end{array}$ & $\begin{array}{ll}\text { - } & \text { Self-care } \\
\text { - } & \text { practices/ethic } \\
\text { - } & \text { Holistic development } \\
\text { - } & \text { Practice and gain } \\
& \text { relational skills }\end{array}$ & $\begin{array}{l}\text { Design programs in which } \\
\text { students develop as whole } \\
\text { people (body, mind, spirit) } \\
\text { by learning how to take care } \\
\text { of themselves, work with } \\
\text { others, and practice } \\
\text { relational leadership. }\end{array}$ \\
\hline
\end{tabular}

As outlined in Table 2, in order to foster SSLD the Student Sustainability Center (SSC) should continue to design its programming around the themes of community, holistic sustainability, and holistic self. The SSC Program Coordinator can focus on creating an environment in which students learn from their peers, engage with different perspectives, and have a safe space to practice leadership, design programs in which students gain a holistic understanding of sustainability and sustainability leadership concepts that they are able to apply within the SSC and other situations, and design 
programs in which students develop as whole people (body, mind, spirit) by learning how to take care of themselves, work with others, and practice relational leadership.

Remaining Research Questions. This section provides answers to the remaining research questions. While these questions relate much more to program considerations and structure than the theoretical inquiry into what supports student sustainability leadership development (SSLD), these themes emerged from the data that illuminate other considerations when attempting to support SSLD.

How do students get involved with sustainability at PSU? All of the students indicated that they began to get involved with co-curricular programming or student employment early on in their educational careers, and most of these students got involved specifically with sustainability-related programs early on. This could indicate that attending campus outreach events in order to reach students early on and providing students opportunities to get involved with sustainability early on are valuable endeavors. Being involved with sustainability and leadership development opportunities early on in their college experiences might allow students to maintain their involvement over time, allowing them to develop these complex ways of knowing and practicing leadership. Further research could investigate sustainability leadership development in students based on time involved in programming.

Additionally, many students mentioned specific people that connected them to the SSC (or other sustainability programs) or people that supported them when they initially began their involvement. This indicates that networks of people involved with sustainability at PSU are important means to promoting students getting involved in sustainability programming. 


\section{What are challenges to being involved with sustainability at PSU? One}

resounding theme that students brought up in relation to the challenges they faced in their degree was finances. This is to be expected, as higher education, and especially PSU, are always facing budget cuts and rising costs. This indicates that being able to provide financial support students to students who want to pursue sustainability work is important to consider when planning programs.

What are the benefits of participating in sustainability programs? As discussed in the first section, community is the main benefit of participating in sustainability programs. Many students got involved with the SSC in order to find community, or stuck with the SSC because of the community. This indicates that the SSC's efforts to foster a diverse community of students who work together should be maintained.

Another theme that emerged from the data was that the sustainability programs at PSU provide students the chance to pursue their interest in sustainability. Some students spoke about how unique the SSC is compared to co-curricular programs at other state universities in Oregon, highlighting that the SSC and the other sustainability programs at PSU are an important and valuable offering to PSU students interested in sustainability.

What is needed to make a valuable education for students? Many students discussed applied sustainability-related projects they were able to engage in at PSU and expressed that they enjoyed, learned from, and valued the opportunity to do sustainability work outside of the classroom. This indicates that students value the chance to practice what they learn and the importance of applied and experiential learning in SSLD. Opportunities for practicing sustainability make a valuable education for students. 
Students cited PSU's connection to Portland, a city known to engage in sustainability efforts, and the institution's sustainability identity as reasons to attend PSU to begin with, indicating that sustainability programs at PSU should leverage PSU's connection to the city and its "green" identity to make a valuable experience for students.

\section{Does the SSC Leadership Fellows (SSLF) curriculum support sustainability}

leadership development? The results overall indicate that the students who participated in the SSLF demonstrated an understanding and application of sustainability leadership principles and ideas. They articulated a holistic understanding of the complexity and interconnectedness of sustainability, described using relational skills, spoke about being committed to the work of sustainability, and recognized the importance of working with and learning from their community, all characteristics of sustainability leadership. This indicates that the SSLF curriculum provides effective student sustainability leadership development opportunities.

\section{Conclusion}

Overall, the results indicate that student sustainability leadership development is supported by three overarching themes: community, holistic sustainability, and holistic self. When students are able to broaden and apply their sustainability knowledge, practice self-care, and develop holistically within a diverse community oriented around sustainability values, they gain the chance to develop and practice sustainability leadership skills and abilities. The SSC should continue to attend to these three components in their pedagogies, curriculum, and design. The next chapter situates these findings within the literature reviewed in Chapter Two, drawing implications from the research about student sustainability leadership development. 


\section{Chapter V \\ Discussion}

This chapter reviews the results of the research and discusses their significance in relation to the content of the Introduction and Literature Review. The implications of the study and recommendations for moving forward are presented in this chapter, as well as a conclusion to the study.

The purpose of this study was to explore what supports student sustainability leadership development at Portland State University (PSU). The results of the study broadly indicate that the Student Sustainability Center (SSC) at PSU "walks the leadership program pedagogy talk" (Eich, 2008, p. 186), or in other words, provides effective sustainability leadership development opportunities for students. The SSC provides students the opportunity to participate in programming and practices that reflect the sustainability leadership values the program holds. This in turn provides students the opportunity to learn about and engage in leadership development aligned with those sustainability values.

While this discussion focuses primarily on the implications of this research in relation to the SSC, it is important to note that students discussed academic and cocurricular programs across PSU when reflecting on their sustainability leadership development. This was the case particularly for two students who were interviewed that were enrolled in a graduate degree program in sustainability leadership, which the SSC Program Coordinator graduated from, that employs similar pedagogies to the SSC.

\section{Student Leadership}


This study found that sustainability leadership development was supported by three themes: community, holistic sustainability, and holistic self. These findings align with the results of Eich's (2008) exploration of high quality student leadership programs, which found that participating in a learning community and experiential learning pedagogies can enhance student learning and leadership development. The Student Sustainability Center (SSC) provides students a community in which students are able to help each other develop as leaders, as well as the chance to practice and enact the leadership concepts they learn. This study also aligns with Dugan and Komvies' (2010) quantitative study of student leadership development in which they found that sociocultural discussions with peers have a major influence on leadership development. The SSC created opportunities for students to engage in socio-cultural discussions by providing an interdisciplinary and diverse community setting for students to come together and discuss topics of and across difference.

While the student participants illustrated that the SSC fostered key aspects of student leadership development, the lack of interview questions explicitly about leadership made it difficult to draw conclusions about students' perceptions of their leadership abilities. The first iteration of this study in 2015 was about engagement, leadership, and understanding what students experienced as they went through the university system. The leadership aspect was implied, as students were told in the recruitment email that they were selected to participate because they were sustainability leaders on campus, so the original researchers chose not to include questions specifically about leadership (H. Spalding, personal communication, July 31, 2019). In the interviews I conducted, only three out of nine students used the term leader or leadership in relation 
to themselves. This could have multiple meanings: that students do not see themselves as leaders or merely that most students did not articulate their view of themselves as leaders, which could have been impacted by the acknowledgement that they were seen as sustainability leaders in the recruitment email. While at first I thought that this might imply that students do not view themselves as leaders, the lack of leadership identification might in fact indicate a complex level of leadership development in students. This finding could align with Komives et al.'s (2005) last stage of leadership identity development, Level 6 Integration/Synthesis:

Even if they did not own the title of leader, they did have a confident identity of a person who does leadership. They understood organizational complexity and practiced systemic thinking. They were comfortable with contextual uncertainty knowing that because they had internalized leadership into their self-concept they could adapt and contribute to a new, unknown context. (p. 607)

Because students demonstrated systems thinking, spoke about their confidence and relational skills, and were committed to doing sustainability work in the present, future, and outside of the SSC context, and when those that did mention leadership it was described as relational, perhaps students had integrated a leadership identity into their sense of self.

The experiential nature of the SSC's co-curricular programming provides students the chance to practice and reflect on their experiences with sustainability leadership, which are effective pedagogies for leadership development, as well as leadership identity and leadership self-efficacy development (Allio, 2005; Komives et al., 2005; Wagner, 2011). If the students in this study had developed an Integrated/Synthesized leadership 
identity (Komives et al., 2005), it could be interpreted that the students' appreciation of their applied experiences with the SSC highlights how important the experiential nature of the SSC was to their development of leadership identities. Students also demonstrated the capabilities of self-reflection through their interviews, specifically when they spoke about themselves doing sustainability work and processing their experiences in their community, which is an important aspect of relational leadership development (Dugan \& Komives, 2010; Eich, 2008; Meixner \& Rosch, 2011; Wagner, 2011). Lastly, students demonstrated a level of self-efficacy when they spoke indirectly about enacting leadership in contexts outside of the SSC, which aligns with mastery, one of Bandura's (as cited in Wagner, 2011) strategies to increase self-efficacy.

Regardless of whether students self-identified as relational leaders, they largely did not speak about positional leaders or hierarchical leadership throughout the interviews, potentially indicating that they do not hold views of leadership that are aligned with industrial leadership philosophies. Further research could specifically assess leadership development with established assessment tools and measures, or could assess relational leadership identity development and self-efficacy in students for a more concrete picture of how student leadership development at PSU aligns with concepts from the literature.

The specific SSC program examined in this research, the Leadership Fellows, is based on of the Social Change Model of Leadership (SCM). The SCM is comprised of seven values that are grouped into three categories: Individual, Group, and Community/Society (Wagner, 2007). Throughout their interviews, the participants demonstrated an understanding of the three levels of the SCM, which can be seen to align 
with the final three categories of the results of this study: community, holistic sustainability, and holistic self (Group, Community/Society, Individual). While I did not analyze the data specifically within the context of the SCM, the similarity in these categories could indicate that the Leadership Fellows is providing student leadership development opportunities that align with the SCM values.

\section{Sustainability Leadership}

In addition to demonstrating characteristics of high quality student leadership programming, which indicates that the SSC provides effective student leadership development opportunities, the results from the study show congruency with sustainability leadership literature as well. In her study of an academic sustainability leadership course, Burns (2016) found that creating community, peer learning, and experiential learning supported sustainability leadership learning in students. Savage et al. (2015), who studied an academic sustainability leadership program, found similar themes: that students were supported by the program's experiential format and community focus. In their study, Shriberg and MacDonald (2013) recommended best practices for sustainability leadership programs similar to those found by Burns (2016) and Savage et al. (2015): employ experiential learning; integrate disciplines; and build community. The three themes found in this master's thesis project (community, holistic sustainability, and holistic self) mirror the importance of community and experiential learning, echoing Burns' (2016), Savage et al.'s (2015), and Shriberg and MacDonald's (2013) research on effective sustainability leadership pedagogies, indicating that the SSC provides effective student sustainability leadership development programming. 
Another finding from Savage et al.'s (2015) research was that personal development was an important aspect of the sustainability leadership program they studied. They describe that "participants felt that personal development exercises enhanced their ability to reach the program's target sustainability leadership outcomes, specifically: attaining personal and emotional attributes that would help them behave sustainably, and, acquiring the skills to act sustainably" (Savage et al., 2015, p. 699). The emphasis on personal development closely echoes the importance of self-care found in this study, implying that self-care and personal development could be seen as a critical piece of helping students develop as sustainability leaders in the SSC programs.

When describing the need for co-curricular sustainability programming in higher education, Kerr and Hart-Steffes (2012) assert that the multifaceted nature of sustainability requires a systems thinking perspective that allows people to see the relationships between stakeholders, writing that successful sustainability initiatives require "the ability to build relationships and trust, leadership skills, and persistence... Notably, these are not necessarily skills learned solely inside the classroom" (p. 8). As iterated by Kerr and Hart-Steffes (2012), a focus on personal development and skills related to personal development in relation to sustainability leadership might be expected in a co-curricular program. However, the academic program Savage et al. (2015) studied included personal development in the program design, which was similar to the academic course that Burns (2016) studied that included learning about and practicing self-care. Most students in this study expressed that they learned self-care from the SSC, while a small number of students expressed that they learned about self-care in their academics. As self-care and personal development have been shown to be important to sustainability 
leadership both theoretically and empirically, this indicates that personal development and self-care should be included in sustainability programs across institutional locations within the academy. It also indicates that the SSC is providing effective sustainability leadership development opportunities for its students by including self-care in its programming, as self-care was one of the sub-themes in the "holistic self" theme from this study.

Another key factor supporting the students' sustainability leadership development in this study was gaining a holistic understanding of sustainability, often by learning specifically about issues of social sustainability, environmental justice, social justice, diversity, inclusion, accessibility, or cultural sustainability. Gaining a holistic understanding of sustainability, characterized by being able to recognize the interconnection of the three pillars of sustainability, economic, social, environmental (National Research Council, 2011), and being able to identify the systems of power at the root of unsustainability have been identified as important aspects of sustainability leadership (Burns, 2016; Evans, 2010; Ferdig, 2007; Ferreira, 2017; Kerr \& Hart-Steffes, 2012; MacDonald \& Shriberg, 2016; Shriberg \& MacDonald, 2013; Wiek, Withycombe, \& Redman, 2011). Burns (2016) describes the importance of learning this content to sustainability leadership:

In order to be effective sustainability leaders, learners need to have the opportunity to explore how their own privilege or oppression is linked to sustainability issues. Understanding how we are embedded in systems of oppression and imprinted with social patterns (such as racism, sexism, classism 
and anthropocentrism) is key to understanding society (Merchant, 1992), and key to making change. (p. 8)

The SSC often provided students the chance to learn about social sustainability and examine their position within social and power structures, indicating that the SSC provides this integral aspect of sustainability leadership development. While some of the students, who took academic courses in disciplines that have a focus on topics related to social sustainability, spoke about learning this content in their curricular experiences, learning about social sustainability in the co-curricular setting of the SSC was invaluable to students whose academics did not cover topics related to social sustainability.

When considered together, the three themes found in this study, community, holistic sustainability, and holistic self, reflect the epistemologies of sustainability leadership. Sustainability leadership recognizes the complexity, interconnection, and relationality of the world. The themes of community, sustainability, and self reflect this holistic philosophy, recognizing that the self, communities, and systems all must change when working towards sustainability and that our minds, bodies, and spirits all play a role in creating this change (Keeling, 2004). These themes further highlight how the SSC provides effective sustainability leadership development programming, or philosophy-inaction that reflects sustainability leadership philosophies and epistemologies.

This research demonstrated how the SSC provides effective student leadership and sustainability leadership development opportunities for PSU students. Their programs could be seen as an integration of student and sustainability leadership theories that have been enacted together effectively in practice, providing an example of combining student affairs and sustainability programming in higher education. There is 
congruency between student and sustainability leadership theories to begin with, as they both have their foundations in the postindustrial leadership paradigm, and the SSC is an example of these theories applied programmatically. This can be seen in the way that students view the Social Change Model of Leadership (Wagner, 2007) levels through a sustainability lens: individual, group, community/society as holistic self, community, holistic sustainability. This can also be seen in the way that students' understanding of sustainability broadened to include the social component through their involvement with the SSC, which aligns with a broadening understanding of leadership as relational and collaborative (Komives et al., 2005). This broadening of understanding reflects the nonhierarchical, nonlinear, deconstructive, and diverse nature of the constructivist epistemologies that underpin student and sustainability leadership (Komives \& Dugan, 2010). This research contributes an understanding of the combination of sustainability and leadership in student affairs in practice to the literature, as well as the idea of a "sustainability lens." Further research could investigate the cultivation and application of a "sustainability lens" by sustainability leaders.

\section{Institutional Implications}

To answer the question of what supports sustainability leadership development at PSU we must think in ways that mirror the multifaceted nature of sustainability itself. Being able to engage in sustainability leadership is a complex and nuanced process that requires cognitive skills to understand the complexity and interconnection of [un]sustainability issues, the relational competencies to work effectively with others, selfawareness, and the values that orient one's work towards creating a better world for themselves and others, human and nonhuman alike. To do this in an institution embedded 
in Western ways of knowing and operating that are based on separation and hierarchy can be a challenge.

To effectively prepare students to be able to engage in sustainability leadership, a practice that embraces the epistemological transition from hierarchical to relational leadership and that cultivates care for life on earth, we need holistic and integrative leadership development opportunities in curricular and co-curricular programming across the institution. While most of the students described the SSC programming as contributing to their student sustainability leadership development, many students also spoke about sustainability in relation to their academics. In order to effectively promote sustainability leadership, PSU should take serious its commitment to sustainability across the institution. As Kerr and Hart-Steffes (2012) write:

In fact, the topic of sustainability is one best taught holistically. Not only must students have opportunities to learn about related topics in the classroom, they must also see a university community role-modeling sustainable behavior through its policy and practice, and they must be provided with opportunities to put classroom knowledge into action in their daily lives. Moreover, because sustainability is about changing our vision for the future, and is a complex and multifaceted issue, this notion of holistic and transformative learning is incredibly applicable. Although classroom learning is essential, it cannot possibly provide the entirety of learning that must occur if a college is expected to prepare future leaders and citizens. (p. 11)

Here, Kerr and Hart-Steffes advocate for recognizing the importance of co-curricular programming that focuses on sustainability. This study demonstrated that the SSC 
provides effective co-curricular opportunities for students to become sustainability leaders, even without participating in academics related to sustainability, by providing them the community that supports their learning and personal development, as well as the chance to broaden and apply their sustainability learning. Learning Reconsidered (Keeling, 2004), a seminal student affairs text, advocates for a similar approach to a college education: transformational and whole person learning across the academy. This approach requires that "teaching and learning include the full scope of a student's life. It cannot be accomplished in the classroom alone-or out of the classroom alone" (Keeling, 2004, p. 11). Sustainability leadership development, cultivated through transformative learning and practice, might be best supported by efforts across the institution.

The results of this study indicate that the Student Sustainability Center should continue its co-curricular programming with focus on the interdisciplinary community it creates, provide students the tools to take care of themselves, and seek to provide opportunities for students to apply their learning, especially learning around social sustainability. Following the theoretical thread from the literature, the question then becomes, how does PSU get more students involved in programs that support holistic sustainability development and provide sustainability content across the academy for undergraduate and graduate students? To gain an understanding of how this might be done, further research could investigate students that are not involved or do not maintain involvement with the SSC to identify barriers to participating, as this study interviewed students who had been successfully involved with the SSC. Further research could also investigate the SSC programming through specific leadership models, such as the Leadership Identity Development Model (Komives et al., 2005) or the Social Change 
Model of Leadership (Wagner, 2007), as well as how student sustainability leaders develop over time or based on the length of their involvement.

\section{Reflexivity}

The master's tools will never dismantle the master's house. Audre Lorde (1984)

This study indicates that sustainability leadership should be promoted and supported across Portland State University (PSU) and while I agree that this would have its benefits, as I imparted in my methods section, I must critically analyze any knowledge production I engage in from multiple perspectives, including my own work on sustainability.

Sustainability leadership and education are often framed as a means to critically create a better world. Burns (2016) describes this aim of sustainability learning:

For many learners, critically questioning and unpacking the underlying causes and various aspects of sustainability problems provides an opportunity to re-frame their understanding of the world and to potentially transform their attitudes and ways of being. Transformative education is thus a key strategy for addressing complex sustainability issues because it challenges dominant hegemonic systems, and can be a form of liberation and transformative cultural change. (p. 3)

As Burns (2016) describes, learning about sustainability in relation to power dynamics has liberatory potential. This attempt at liberatory transformation can be seen in this study from the inclusion of social sustainability in the Student Sustainability Center (SSC) curriculum, exemplified by students articulating their learning about issues related to critical sustainability, such as of gentrification in Portland and Indigenous perspectives on 
sustainability. These components of the SSC curriculum reflect an attempt to challenge dominant hegemonic systems.

Because this study focused on sustainability leadership, the implications I have drawn sit within these discourses. However, I want to urge those working in sustainability at PSU to critically examine the work they do and the philosophies they hold and teach. As I described in Chapter I, sustainability as a discourse and field of study, even as an epistemology, arose from within the context of ongoing settler colonialism in what is now known as the United States. Applying the lens of a Critical Indigenous scholar, Jodi Byrd (2011) of the Chickasaw Nation, can assist in analyzing sustainability within the context of settler colonialism. Using this lens allows us to see that given sustainability's history and origin within settler-colonial mindsets and systems, sustainability's attempt at finding solutions to the power imbalances, ecological destruction, and social ills that are transited across the globe by settler colonialism might be misguided (Byrd, 2011). Seeing as sustainability originated from the dominant hegemonic systems of global European colonialism, the sustainability movement can actually be understood as continuing the erasure of Indigenous issues and presence on land (Byrd, 2011). The inclusion of social sustainability into the curriculum of the SSC and other sustainability programs across PSU attempts to critically unpack and challenge dominant hegemonic systems and ways of knowing. But we have to ask ourselves, even with this social sustainability perspective, who is this sustainability for? If we leave the fact unchallenged that sustainability is for the most part about imagining a future with settlers on the Indigenous land that became known as the United States, the discourse is inherently continuing to serve the violent processes and structures of settler colonialism. 
This erasure of the current and ongoing settler colonialism taking place on this land can be seen in many sustainability texts. For example, in her article, Sustainable Leadership Toward Restoring the Human and Natural Worlds, Evans (2018) gives an explanation of how colonialism has created unsustainable conditions across the world while simultaneously failing to recognize the ongoing settler colonialism taking place in the very place from which she writes, representing a fundamental erasure of the project of settler colonialism and an incomplete critique of the systems that cause unsustainability. The exploration that this perspective provides is unsettling, as it brings into question the very nature and ethics of the well-intentioned work that sustainability educators and leaders do. However, these questions must be explored and their implications heard and accounted for. In order to truly dismantle the systems that cause unsustainability, we will need to engage in reflexive practices that seek to dismantle all of the systems that cause unsustainability, including settler colonialism, even if it means that ourselves and our work are implicated in upholding these structures of violence.

While there are many structures and systems of violence that need to be examined, I believe that settler colonialism is an important concept for all sustainability work to engage with and be held accountable to. This is because all sustainability work inherently has to do with land and because Indigenous perspectives are often folded into sustainability work only to serve the purpose of sustainability, rather than for their own methodological, epistemological, or material aims (Smith, 2012). For example, leaders and scholars that propose more sustainable ways for settler society to live on this land are essentially attempting to ensure settler futurity on stolen Indigenous land. The implication of sustainability without a decolonial lens is that the work seeks to extend and sustain 
settler colonialism. This in the end only furthers the settler colonial project, leaving one of the dominant hegemonic systems that sustainability seeks to challenge fully intact.

People working in sustainability need not shy away from this unsettling work, rather we should embrace the questions and solutions brought forward by engaging in this reflexive practice of hearing those marginalized by the systems of settler colonialism. How can sustainability educators and leaders hold themselves accountable to acknowledging the harms of settler colonialism and orient their work to be in active solidarity with communities resisting colonialism, and thus unsustainability? I believe that all future research on the topic of sustainability leadership, as well as sustainability leadership programs, should ask this question.

\section{Conclusion}

Student sustainability leadership development in higher education can play an important role in cultivating people who are able to facilitate collective action towards sustainable change. As found in this study, student sustainability leadership development was fostered through university programming that provided students the opportunity to be part of an interdisciplinary and diverse community that shared sustainability values, that helped students cultivate a holistic understanding of sustainability concepts and praxis, and that promoted the development of whole people through self-care and developing relational abilities in community. These findings align with much of the existing literature on student and sustainability leadership, implying that the Student Sustainability Center at Portland State University (PSU) provides effective sustainability leadership development opportunities for students. If institutions such as PSU are committed to developing leaders who are able to help solve the sustainability challenges 
we face today, they might consider supporting sustainability efforts across the institution that encourage academics to include and attend to the affective dimensions of students and that encourage student affairs to connect to curricular concepts (Keeling, 2004). This integrated approach to sustainability leadership must be considered as we move forward, as leadership must reflect and practice the values it purports to hold. Issues of unsustainability and the mindsets that cause them can only be countered by the ability to recognize relationships within systems, act on sustainability values, and by cultivating whole people. Sustainability leadership should consider an approach that is held accountable to and involves working alongside those marginalized the most (on their terms) by the dominant hegemonic systems of colonialism. This is especially true of Indigenous voices when doing sustainability work, as these voices will be the ones who can guide the way in dismantling the systems that cause unsustainability. As we move into an unknown and unprecedented future for humanity, the need for people who can engage in critical relationality will grow. While this study was not meant to be generalizable, it can perhaps illuminate potential pathways for developing people who are equipped to guide us into a more just and sustainable future. 


\section{References}

“About SALP”. (2019). Retrieved April 4, 2019, from https://www.pdx.edu/studentleadership/about-salp

“Awards \& Certifications". (2019). Retrieved April 1, 2019, from https://www.pdx.edu/sustainability/awards-certifications

"About Us". (2019). Retrieved April 1, 2019 from https://www.pdx.edu/studentsustainability-center/about-us

Allio, R. (2005). Leadership development: teaching versus learning. Management Decision, 43(7), 1071-1077.

Ardichvili, A., Natt och Dag, K., \& Manderscheid, S. (2016). Leadership development: Current and emerging models and practices. Advances in Developing Human Resources, 18(3), 275-285.

Bendell, J., \& Little, R. (2015). Seeking sustainability leadership. Journal of Corporate Citizenship, (60), 13-26.

Brungardt, C. (1996). The making of leaders: A review of the research in leadership development and education. Journal of Leadership studies, 3(3), 81-95.

Brundtland, G. (1987). Report of the World Commission on Environment and Development: Our Common Future. United Nations General Assembly document A/42/427.

Burns, H. L. (2016). Learning sustainability leadership: An action research study of a graduate leadership course. International Journal for the Scholarship of Teaching and Learning, 10(2), 1-11. 
Burns, H., Diamond-Vaught, H., \& Bauman, C. (2015). Leadership for sustainability: Theoretical foundations and pedagogical practices that foster change. International Journal of Leadership Studies, 9(2), 88-100.

Byrd, J. A. (2011). The transit of empire: Indigenous critiques of colonialism. U of Minnesota Press.

Carter, N., Bryant-Lukosius, D., DiCenso, A., Blythe, J., \& Neville, A. J. (2014, September). The use of triangulation in qualitative research. Oncology nursing forum, 41(5), 545-547.

Charmaz, K. (2014). Constructing grounded theory (2nd ed., Introducing qualitative methods). London ; Thousand Oaks, Calif.: Sage.

Creswell, J. (2003). Research design : Qualitative, quantitative, and mixed methods approaches (2nd ed.). Thousand Oaks, Calif.: Sage Publications.

Creswell, J. (2007). Qualitative inquiry \& research design : Choosing among five approaches (Second ed.). Thousand Oaks: Sage Publications.

Day, D. V., Fleenor, J. W., Atwater, L. E., Sturm, R. E., \& McKee, R. A. (2014). Advances in leader and leadership development: A review of 25 years of research and theory. The leadership quarterly, 25(1), 63-82.

de Guerre, D. W., \& Taylor, M. M. (2004). Graduate leadership education in a socioecological perspective: Working at the paradigmatic interface. In Learning toward an ecological consciousness: Selected transformative practices (pp. 65-83). Palgrave Macmillan, New York. 
Dugan, J. P., \& Komives, S. R. (2010). Influences on college students' capacities for socially responsible leadership. Journal of College Student Development, 51(5), $525-549$.

Dugan, J. P., \& Komives, S. R. (2011). Leadership Theories. In Komives, S. R., Dugan, J. P., Owen, J. E., Wagner, W., \& Slack, C. (Eds.), The Handbook for Student Leadership Development (2nd ed., pp. 35-58). San Francisco, CA: John Wiley \& Sons.

Eich, D. (2008). A grounded theory of high-quality leadership programs: Perspectives from student leadership development programs in higher education. Journal of Leadership \& Organizational Studies, 15(2), 176-187.

Evans, T. L. (2010). Critical social theory and sustainability education at the college level: Why it's critical to be critical. Journal of Sustainability Education, 1, 1-16.

Evans, T. L. (2018). Sustainable Leadership: Toward Restoring the Human and Natural Worlds. In Redekop, B. W., Gallagher, D. R., \& Satterwhite, R. (Eds.). Innovation in Environmental Leadership: Critical Perspectives. Routledge.

Ferdig, M. A. (2007). Sustainability leadership: Co-creating a sustainable future. Journal of Change Management, 7(1), 25-35.

Ferreira, F. (2017). Critical sustainability studies: A holistic and visionary conception of socioecological conscientization. Journal of Sustainability Education, 13.

Grande, S. (2004). Red pedagogy: Native American social and political thought. Lanham, Maryland: Rowman \& Littlefield. 
Hull, R. B., Robertson, D., \& Mortimer, M. (2018). Wicked Leadership Competencies for Sustainability Professionals: Definition, Pedagogy, and Assessment. Sustainability: The Journal of Record, 11(4), 171-177.

Keeling, R. (2004). Learning reconsidered : A campus-wide focus on the student experience. Washington, D.C: ACPA : NASPA.

Kerr, K. G., \& Hart-Steffes, J. S. (2012). Sustainability, student affairs, and students. New Directions for Student Services, 2012(137), 7-17.

Komives, S. R. (2011). Advancing Leadership Education. In Komives, S. R., Dugan, J. P., Owen, J. E., Wagner, W., \& Slack, C (Eds.), The Handbookfor Student Leadership Development (2nd ed., pp. 1-34). San Francisco, CA: John Wiley \& Sons.

Komives, S. R., \& Dugan, J. P. (2010). Contemporary leadership theories. Political and civic leadership: A reference handbook, 1, 111-120.

Komives, S. R., Dugan, J. P., Owen, J. E., Wagner, W., \& Slack, C. (2011). The Handbook for Student Leadership Development. John Wiley \& Sons.

Komives, S. R., Lucas, N., \& McMahon, T. R. (2013). Exploring leadership : For college students who want to make a difference. Retrieved from https://ebookcentral-proquest-com.proxy.lib.pdx.edu

Komives, S. R., Longerbeam, S. D., Mainella, F., Osteen, L., Owen, J. E., \& Wagner, W. (2009). Leadership identity development: Challenges in applying a developmental model. Journal of Leadership Education, 8(1), 11-47. 
Komives, S. R., Longerbeam, S. D., Owen, J. E., Mainella, F. C., \& Osteen, L. (2006). A leadership identity development model: Applications from a grounded theory. Journal of College Student Development, 47(4), 401-418.

Komives, S. R., Owen, J. E., Longerbeam, S. D., Mainella, F. C., \& Osteen, L. (2005). Developing a leadership identity: A grounded theory. Journal of College Student Development, 46(6), 593-611.

MacDonald, L., \& Shriberg, M. (2016). Sustainability leadership programs in higher education: alumni outcomes and impacts. Journal of Environmental Studies and Sciences, 6(2), 360-370.

Meixner, C., \& Rosch, D. (2011). Powerful Pedagogies. In Komives, S. R., Dugan, J. P., Owen, J. E., Wagner, W., \& Slack, C (Eds.), The Handbook for Student Leadership Development (2nd ed., pp. 307-338). San Francisco, CA: John Wiley \& Sons.

National Research Council. (2011). Sustainability and the US EPA. National Academies Press.

Portland State University Strategic Plan 2016-2020 [PDF file]. (n.d.). Retrieved from: https://www.pdx.edu/president/sites/www.pdx.edu.president/files/StrategicPlan20 16-4.pdf

Rost, J. C. (1997). Moving from individual to relationship: A postindustrial paradigm of leadership. Journal of Leadership Studies, 4(4), 3-16.

Savage, E., Tapics, T., Evarts, J., Wilson, J., \& Tirone, S. (2015). Experiential learning for sustainability leadership in higher education. International Journal of Sustainability in Higher Education, 16(5), 692-705. 
Shriberg, M. (2012). Sustainability leadership as 21 st century leadership. Environmental leadership: A reference handbook, 2, 469-480.

Shriberg, M., \& MacDonald, L. (2013). Sustainability leadership programs: Emerging goals, methods \& best practices. Journal of Sustainability Education, 5(1).

Smith, L. T. (2012). Decolonizing methodologies: Research and indigenous peoples. Zed Books Ltd..

Spalding, H. E., Williams, D. R., \& Wise, V. L. (2014). Designing and assessing learning outcomes: A framework for co-curricular sustainability programs. Journal of Sustainability Education, 6.

Strauss, A., \& Corbin, Juliet M. (1998). Basics of qualitative research: Techniques and procedures for developing grounded theory (2nd ed.). Thousand Oaks: Sage Publications.

Student Sustainability Center 2016-17 Impact Report [PDF file]. (n.d.). Retrieved from: https://www.pdx.edu/syndication/sites/www.pdx.edu.syndication/files/201617\%20SSC\%20Impact\%20Report.pdf

Student Sustainability Center 2017-18 Impact Report [PDF file]. (n.d.). Retrieved from: https://drive.google.com/drive/u///folders/1S9bgoPgphpEAEQ9BsJsgsuWFifgOf $\mathrm{OMt}$

Sustainability Leadership Center 2009-10 Report [Google document]. (n.d.). Retrieved from:https://docs.google.com/document/d/1fdcnb2ilb9p_hz7_Z7y0lee2JzdPwAe YFFN5ZKs9tI4/edit

“Temi". (2019). Retrieved from: https://www.temi.com/ 
"The James F. and Marion L. Miller Foundation Gift”. (2019). Retrieved from:

https://www.pdx.edu/sustainability/the-james-f-and-marion-1-miller-foundationgift

Tuck, E., \& Yang, K. W. (2012). Decolonization is not a metaphor. Decolonization: Indigeneity, education \& society, 1(1).

Wagner, W. (1996). The social change model of leadership: A brief overview. Leadership, 11, 8-10.

Wagner, W. (2011). Considerations of Student Development in Leadership. In Komives, S. R., Dugan, J. P., Owen, J. E., Wagner, W., \& Slack, C (Eds.), The Handbook for Student Leadership Development (2nd ed., pp. 85-108). San Francisco, CA: John Wiley \& Sons.

"Welcome”. (n.d.). Retrieved, from https://sites.google.com/a/pdx.edu/leadershipfellows-at-portland-state/home

Wheatley, M. J. (2006). Leadership and the new science. San Francisco: Berrett-Koehler Publishing.

Wiek, A., Withycombe, L., \& Redman, C. L. (2011). Key competencies in sustainability: a reference framework for academic program development. Sustainability science, 6(2), 203-218.

Visser, W., \& Courtice, P. (2011). Sustainability leadership: Linking theory and practice. Retrieved from: https://ssrn.com/abstract=1947221. 


\section{Appendix A: Student Sustainability Center Leadership Fellows Syllabus (2017-18) Course Overview}

\section{COURSE OVERVIEW}

\section{Instructional/Learning Needs:}

If you require accommodations (e.g. special seating, interpreter, note-taker, etc.), please inform your facilitators immediately. Students with disabilities should register with the PSU Disability Resource Center (503-725-4150) to document their need for accommodations and obtain support services. We will work with you to arrange the supports you need in this class.

\section{Course Description:}

The Leadership Fellows Program is a one year academic program offered through Student Activities and Leadership Programs (SALP) at Portland State University. The goals of the Leadership Fellows Program are to develop your leadership skills to better serve your organization; develop understanding, knowledge, and skills that you can use in your career and community work; and to meet other student organization leaders and share insights.

\section{Learning Objectives:}

The Leadership Fellows course is designed with specific learning outcomes that each cohort will spend time on. Below are the learning outcomes for this particular section of Leadership Fellows:

2017-18 SALP learning outcome: Congruence

\section{Student Sustainability Center learning outcomes:}

1. Building relationships and systems

2. Knowledge and awareness

3. Civic engagement

4. Sustainability leadership

5. Purposeful pathways 


\section{Appendix B: Recruitment Email}

Hello,

My name is Megan Schneider and I am currently working on my master's thesis in partnership with Heather Spalding of the Student Sustainability Center.

Our project is looking at student sustainability leadership development here at PSU. You have been identified as a sustainability leader who has made significant impacts on our campus community through your participation in the Student Leadership Council or other SSC programs.

Because of your experience, I am interested in scheduling an interview with you to hear your story. These stories will help us identify patterns between sustainability leaders at PSU in order to better support the development of student leaders such as yourself.

Please let me know if you are interested and have time to schedule an hour to chat in the next few weeks. And feel free to let me know if you have any questions.

I look forward to meeting with you!

Megan Schneider 


\section{Appendix C: Study Consent Form}

\section{Portland State University \\ Consent to Participate in Research \\ Sustainability Leader Interviews}

\section{INTRODUCTION}

You are being asked to participate in a research study that is being led by Heather Spalding,

who is the Principal Investigator and Megan Schneider, a graduate student in the Leadership for Sustainability Education program, at Portland State University in Portland, Oregon. This research is studying the patterns and experiences that support the development of student sustainability leaders on campus and documenting and sharing student stories to demystify the pathways for other students to become involved in sustainability programs.

You are being asked to participate in this study because you have or had a sustainability leadership role in a sustainability program.

This form will explain the research study, and will also explain the possible risks as well as the possible benefits to you. We encourage you to talk with your family and friends before you decide to take part in this research study. If you have any questions, please ask one of the study investigators.

What will happen if I decide to participate?

If you agree to participate, the following things will happen:

You will be asked a series of interview questions about your impressions and experiences of being a student and sustainability leader at PSU. You may see the interview questions and have the option of skipping or not answering any question asked. Your answers will be digitally recorded for transcript purposes and saved on a secure, password protected network drive for confidentiality.

Your responses may be published and distributed in electronic and paper form so that other students will be able to learn about your experience. You may also be asked to provide and share a picture of yourself as part of the publication. You will have the opportunity to review, edit, and/or remove any information for publication before it is finalized. You will also have the option to request the removal of any published piece from distribution at a later date.

How long will I be in this study?

Participation in this study will take a total of 2-3 hours over a period of one day. 
What are the risks or side effects of being in this study?

There are risks of stress, emotional distress, inconvenience and possible loss of privacy and confidentiality associated with participating in a research study.

Additional risks include the potential for social stigmatization from the publication of your responses. You may request the immediate removal of any published piece from distribution at any time if desired. If you convey or exhibit signs of psychological/emotional distress during the interview, the PI or Volunteer Coordinator will refer you an appropriate campus resource and/or walk you to counseling services in the Student Health and Counseling Center for priority admittance.

For more information about risks and discomforts, ask the investigator.

What are the benefits of being in this study?

The benefits of being in this study are recognition as a sustainability leader, reflection on your experience, understanding the interconnectedness of your experience in the development of soft and hard skills, and having professional publications for professional development use.

How will my information be kept confidential?

We will take measures to protect the security of all your personal information, but we cannot guarantee confidentiality of all study data. All data will be stored on a secure, password protected network drive. You will be notified and have the opportunity to review and/or decline any information being made publically available.

Information contained in your study records is used by study staff. The Portland State University Institutional Review Board (IRB) that oversees human subject research and/or other entities may be permitted to access your records, and there may be times when we are required by law to share your information. It is the investigator's legal obligation to report child abuse, child neglect, elder abuse, harm to self or others or any lifethreatening situation to the appropriate authorities, and; therefore, your confidentiality will not be maintained.

Will I be paid for taking part in this study?

No, you will not be paid for taking part in this study.

Can I stop being in the study once I begin? 
Your participation in this study is completely voluntary. You have the right to choose not to participate or to withdraw your participation at any point in this study without penalty or loss of benefits to which you are otherwise entitled.

Whom can I call with questions or complaints about this study?

If you have any questions, concerns or complaints at any time about the research study, Heather

Spalding or her associates will be glad to answer them at 503-725-5598.

Whom can I call with questions about my rights as a research participant?

If you have questions regarding your rights as a research participant, you may call the PSU

Office for Research Integrity at (503) $725-2227$ or 1(877) 480-4400. The ORI is the office that supports the PSU Institutional Review Board (IRB). The IRB is a group of people from PSU and the community who provide independent oversight of safety and ethical issues related to research involving human participants. For more information, you may also access the IRB website at https://sites.google.com/a/pdx.edu/research/integrity.

\section{CONSENT}

You are making a decision whether to participate in this study. Your signature below indicates that you have read the information provided (or the information was read to you). By signing this consent form, you are not waiving any of your legal rights as a research participant.

You have had an opportunity to ask questions and all questions have been answered to your satisfaction. By signing this consent form, you agree to participate in this study. A copy of this consent form will be provided to you.

$\overline{\text { Name of Adult Subject (print) }} \quad \overline{\text { Signature of Adult Subject }} \quad$ Date

\section{INVESTIGATOR SIGNATURE}

This research study has been explained to the participant and all of his/her questions have been answered. The participant understands the information described in this consent form and freely consents to participate.

Name of Investigator/ Research Team Member (type or print) 
(Signature of Investigator/ Research Team Member)

Date 


\section{Appendix D: Semi-Structured Interview Questions}

\section{STUDENT SUSTAINABILITY LEADER INTERVIEW QUESTIONS}

1. Why did you choose to attend PSU?

2. How did you initially get involved on campus?

3. Why did you get involved?

4. Did your classes and co-curricular experiences both cover sustainability?

5. What challenges have you faced during your education?

6. What was your first impression of sustainability at PSU? Where did this message come from?

7. What was your first sustainability course?

8. What are the most important sustainability concepts you learned about during your education?

9. What were the specific sustainability skills you gained, and where did you gain them?

10. How did you maintain balance between co-curricular and academic responsibilities?

11. What strategies did you implement to remain resilient and take care of yourself?

12. How would you describe the overall student sustainability experience at PSU?

13. What does college success mean to you?

14. What skills were most important to your success?

15. What are your plans for the future? How does sustainability fit into them?

For Past Students/Graduates Only

16. Describe your transition from student to graduate

17. How did your experience with sustainability at PSU affect your post-graduate life? 